\title{
Revisiting Heck-Mizoroki reactions in ionic liquids
}

Cite this: DOI: $10.1039 / \mathrm{c} 3 \mathrm{ra} 43493 \mathrm{a}$

Received 16th May 2013,

Accepted 29th July 2013

DOI: $10.1039 / c 3 r a 43493 a$

www.rsc.org/advances

\author{
Carla I. M. Santos, ${ }^{\text {ab }}$ Joana F. B. Barata, ${ }^{\text {ac }}$ M. Amparo F. Faustino, ${ }^{a}$ Carlos Lodeiro*b \\ and M. Graça P. M. S. Neves*a
}

The use of ionic liquids as an alternative to conventional organic solvents has been an important research topic in order to answer economic and environmental challenges. This critical review revisits the different approaches and achievements on the use of ionic liquids as solvents in Heck Mizoroki coupling reactions; a brief reference to supported ionic liquids will be also highlighted.

\section{Introduction}

In the last decade the possibility of using ionic liquids (ILs) as an alternative to organic solvents has received the attention of many researchers in order to answer some economic and environmental concerns associated with more conventional chemical processes. ${ }^{1-3}$

ILs are generally defined as salts which melt below $100{ }^{\circ} \mathrm{C}$ to afford liquids composed usually of an organic cation and of an inorganic anion. The free-flowing liquids at room temperature are usually called room temperature ionic liquids and

${ }^{a}$ QOPNA and Department of Chemistry, University of Aveiro, 3810 193, Aveiro, Portugal. E mail: gneves@ua.pt; Fax: +351 234370 084; Tel: +351 234370710 ${ }^{b}$ REQUIMTE CQFB, Chemistry Department, Faculty of Science and Technology, University NOVA of Lisbon, 2829 516, Monte de Caparica, Portugal. E mail: cle@fct.unl.pt; Fax: +351 212948550; Tel: +351210934720 ${ }^{c}$ CICECO and Department of Chemistry, University of Aveiro, 3810 193, Aveiro, Portugal have real advantages when compared with higher melting salts in terms of practical handling. ${ }^{4-9}$

Although the first room temperature IL $\left[\mathrm{EtNH}_{3}\right]\left[\mathrm{NO}_{3}\right]$, with a melting point of $12{ }^{\circ} \mathrm{C}$ was discovered in $1914,{ }^{10}$ the real interest in this field only started with the development of binary ILs based on mixtures of aluminum(III) chloride and $N$-alkylpyridinium or 1,3-dialkylimidazolium halides. ${ }^{5}$

In the composition of ILs the organic cations can be based on asymmetric alkylammonium (1) and alkylphosphonium (2) salts, on heteroaromatics salts like $N, N^{\prime}$-dialkylimidazolium (3), $N$-alkylpyridinium (4) or $N, N^{\prime}$-dialkylpyrazolinium (5) which present low symmetry, weak intermolecular interactions and low charge densities (Fig. 1). The anions can include chloride $[\mathrm{Cl}]$, bromide $[\mathrm{Br}]$, hexafluorophosphate $\left[\mathrm{PF}_{6}\right]$, tetrafluoroborate $\quad\left[\mathrm{BF}_{4}\right], \quad$ trifluoromethanesulfonate $\left[\mathrm{CF}_{3} \mathrm{SO}_{3}\right]$, bis(trifluoromethylsulfonyl)imide $\left[\mathrm{NTf}_{2}\right]$; more recently, organic anions such as $\left[\mathrm{RCO}_{2}\right]$ have also been introduced. ${ }^{8}$

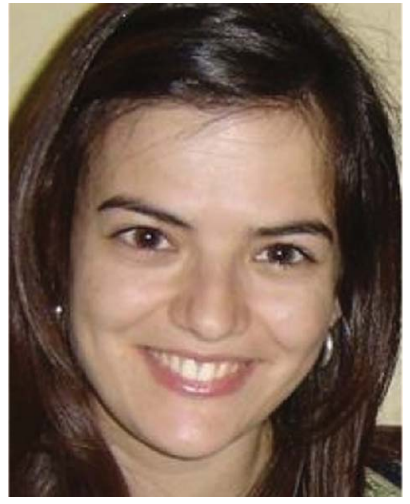

Carla I. M. Santos
Carla I. M. Santos obtained her degree in chemistry from the University of Évora (Portugal) in 2007. Since 2010 she has been a PhD student in the BIOSCOPE research group at the University Nova of Lisbon, REQUIMTE (FCT$U N L)$ and in QOPNA group at the University of Aveiro. Her scientific interests are focused on the synthesis, characterization and exploration of new corrole macrocycles as fluorescent chemosensors in supramolecular chemistry.

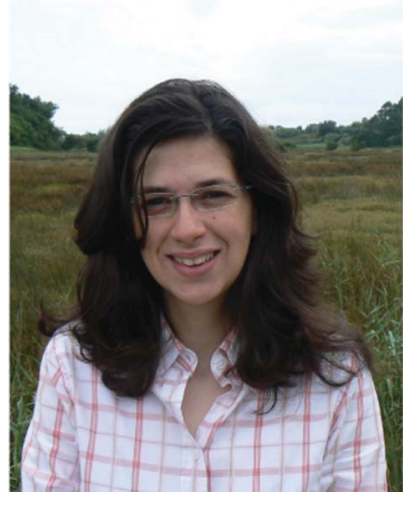

Joana F. B. Barata received her BSc degree (2001) from University of Aveiro, Portugal. She obtained her MsC degree (2004) in Chemistry-Natural Products and Food Chemistry and her PhD degree (2009) in Chemistry at the University of Aveiro, both under the supervision of Prof José Cavaleiro and Prof Maria Graça Neves. Since 2010 she has been working with Prof Tito Trindade, Prof J. Cavaleiro and Joana F. B. Barata Prof. M. G. Neves as a PostDoctoral Research Fellow. She has been awarded with the "Dow Portugal Prize" (2001) and PYCA prize-Portuguese young chemists award (2010). Her research interests are the chemistry of corrole macrocycles and its application as nanomaterials. 


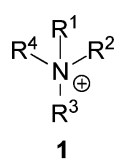$$
\mathrm{R}^{4} \underset{\substack{\mathrm{P}_{1} \\ \mathrm{R}^{3}}}{\mathrm{R}^{1}-\mathrm{R}^{2}}
$$

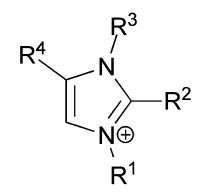

3
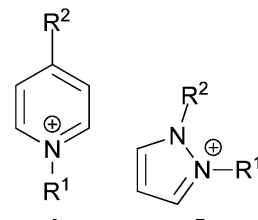

5
Fig. 1 General structures of main organic cations used in ILs.

ILs based on imidazolium cationic units (3) are clearly the most studied ones and the so-called first generation bearing chloroaluminates as the anion (Fig. 2), were reported in 1982 by Wilkes et al. ${ }^{11}$ In 1992 the replacement of that moisturesensitive anion by $\left[\mathrm{BF}_{4}\right]$ or $\left[\mathrm{PF}_{6}\right]$ ions afforded air stable ILs, which have found increasing applications as reaction media for various kinds of organic reactions. These two generations of ionic ILs are usually denominated in the literature as common ILs. $^{9}$

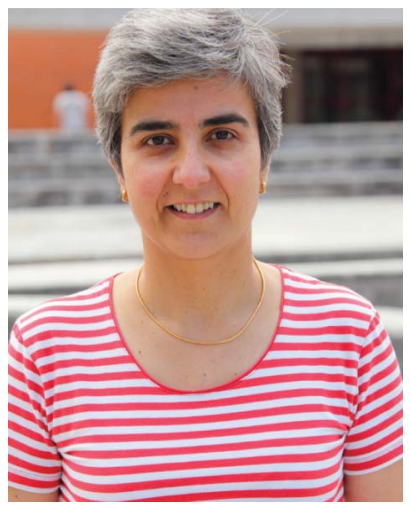

M. Amparo F. Faustino received her doctoral degree in Chemistry from University of Aveiro, in 1999. She is currently working as Assistant Professor in Department of Chemistry, University of Aveiro. His current area of research includes synthesis and transformation of tetrapyrrolic derivatives and their applications.

\section{Amparo F. Faustino}
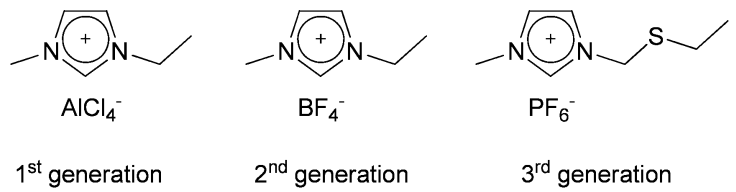

$3^{\text {rd }}$ generation

Fig. 2 The three ILs generations.

The third generation, introduced by Davis ${ }^{12}$ already in this new millennium, includes task-specific ionic liquids (TSILs), where the anion or the cation or both incorporate covalently a functional group, as part of its structure. The modification of the cationic or anionic components allows that the IL can be applied in specific applications. ${ }^{13-16}$

Common ILs are commercially available or can be easily prepared from commercially available reagents using conventional or less conventional heating. ${ }^{17-21}$ Most synthetic procedures to prepare ILs feature initial alkylation of $N$-containing organic bases (amines and $N$-heterocycles) with alkylhalides, followed by metathesis to exchange the anion. In this review, when considered necessary, the access to some sophisticated ILs will be discussed.

ILs exhibit very attractive physical and chemical properties responsible by a high number of applications. These compounds reveal low viscosity, negligible vapour pressure, high polarity, high thermal and chemical stability and potential to be reused and recycled. ${ }^{22}$

Apparently they are also immiscible with many organic solvents. For instance, ILs such as 1-butyl-3-methylimidazolium hexafluorophosphate $[\mathrm{bmim}]\left[\mathrm{PF}_{6}\right]$, are being virtually insoluble in water and alkanes but are able to dissolve many transition metal catalysts. Due to these features they are being used for example in liquid-liquid extractions involving organic systems, as solvents for organic and catalytical transforma-

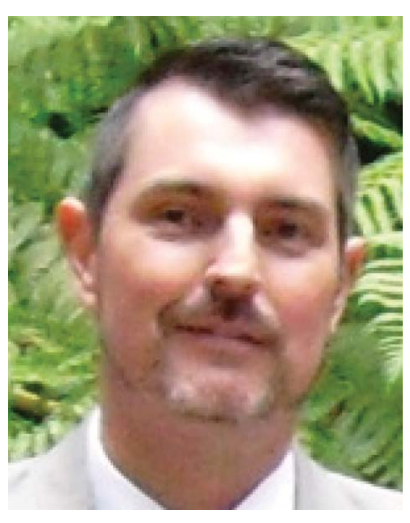

Carlos Lodeiro
Carlos Lodeiro received his $\mathrm{PhD}$ in chemistry in 1999 from the University of Santiago de Compostela, Spain. In 2004 became a fellow researcher and invited lecturer at the REQUIMTECQFB, Chemistry Department (UNL), in Portugal. In 2009 he moved to Spain as an Isidro Parga Pondal researcher-lecturer at the University of Vigo, Spain. Presently he is Assistant Professor at REQUIMTE-CQFB, CD (UNL) and co-head of the BIOSCOPE research group. His research interest comprises (i) physical-organic and inorganic chemistry of fluorescence chemosensors, (ii) synthesis of fluorescent and colorimetric chemosensors, (iii) nanoparticle synthesis and functionalization, (iv) supramolecular analytical proteomics and (v) biomarker discovery.

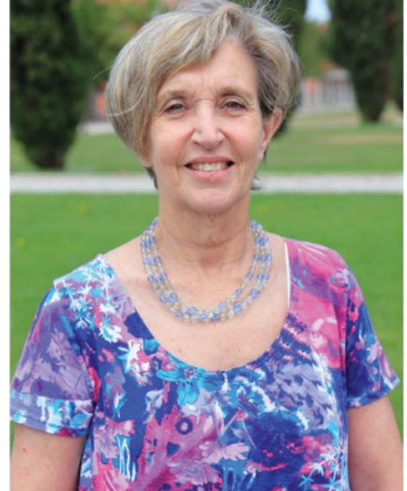

Maria da Graça P. M. S. Neves is Associated Professor with Habilition at the Department of Chemistry, University of Aveiro (UA). She obtained her Habilition (Agregação) and PhD by UA, her Master degree by UMIST, Manchester, Great-Britain and her Degree (Licenciatura) in Chemistry by University of Lourenço Marques, Mozambique. Her research interests are centered on the synthesis functionalization and potential M. Graça P. M. S. Neves applications of tetrapyrrolic macrocycles like porphyrins, corroles and phthalocyanines. 
tions namely the ones mediated by transition-metal, as novel electrolytes for electrochemical process, production of novel materials and more recently, in the synthesis of nanoparticles and other inorganic nanostructures. ${ }^{23}$ In particular, IL can be used as an important alternative to the rather reactive water in catalytical transformations involving organometallic without requiring any change in either the ligand or the organic phase.

The studies realized show that the use of IL in catalytic processes reduce the emission of toxic gases into the atmosphere and maximize the yield, selectivity and separation of final product. $^{24}$ Initially, in those transformations it was thought that ILs due to their weak tendency to coordinate had an innocent role. However, recent experimental evidences contradict the situation and the literature reviewed suggests that in a catalytic process an IL can act as the solvent, but also as catalyst or co-catalyst. ${ }^{6,25-27}$

In the last years, the importance of IL has been extensively investigated and reviewed. ${ }^{28-30}$ Various advantages have been observed, namely, in the activation of the catalyst, improvement of its stability, immobilization and recyclability, facilitating product isolation and influencing the selectivity of the reaction.

In the following sections, a review of the work considering Heck-Mizoroki reactions performed in IL will be revisited. In the last decade a reasonable number of papers on this topic clearly shows its importance in organic synthesis.

\section{Heck-Mizoroki reactions in ionic liquid}

It is well known that the introduction of synthetic methodologies based on transitions metals can give access to products that could not be available if more conventional synthetic methodologies were considered. Most of these powerful and efficient tools, namely the ones involved in the formation of carbon-carbon bonds are centred in well-known transformations catalyzed by palladium(0) such as the Heck-Mizoroki, Suzuki-Miyaura, Migita-Kosugi-Stille and Sonogashira reactions. ${ }^{31,32}$

Academic and industrial interest in these reactions increased in recent years, due to the development of more efficient catalyst systems and the discovery of waste-free versions. Also, problems associated with the decomposition and leaching of expensive catalytic systems and for instance, laborious product isolation, low activities and selectivities were solved.

The possibility of using IL to answer the economic and environmental concerns associated with the conventional homogeneous and heterogeneous cross-coupling procedures was responsible for the considerable attention given to the use of ILs as a green alternative in transformations mediated by transition-metal complexes. The success of IL in this field is demonstrated by the number of publications and reviews that appeared after the first reports., ${ }^{43-36}$

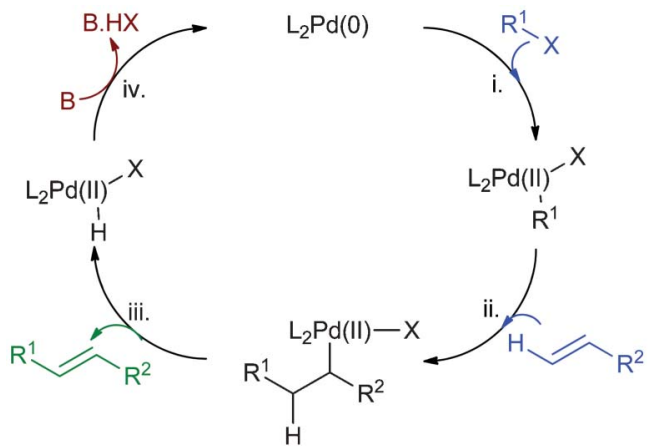

Fig. 3 Simplified catalytic cycle of Heck Mizoroki reaction.

In order to simplify the recent developments of HeckMizoroki reactions in ILs, some considerations about this coupling reaction will be referred first.

\section{General comments on Heck-Mizoroki reactions}

The cross-coupling of organic halides with alkenes in the presence of catalytical amounts of $\operatorname{Pd}(0)$ and a base was reported in 1970, independently, by the research groups led by Mizoroki ${ }^{37}$ and by Heck. ${ }^{38}$ The significance of this chemistry was recognized by award of the 2010 Nobel Prize in Chemistry to Professor Richard Heck together with Professors Ei-ichi Negishi and Akira Suzuki. ${ }^{39,40}$

In these reactions the alkene can be neutral, rich or poor in electrons and the best selectivities are usually obtained in presence of electron-poor alkenes (Fig. 3). The $\mathrm{R}^{1}$ group of the halide, adds to the least hindered end of the alkene affording the thermodynamically favourable $E$ substituted-alkene. In the presence of electron-rich alkenes the aryl group is added to both ends but an improvement in the control can be achieved if adequate electron-donating are present like enol ethers or enamines; in this case the addition of $\mathrm{R}^{1}$ occurs next to the heteroatom. The organic halides or pseudo-halides (e.g. triflates, diazonium salts) can be of aryl, alkenyl or heteroaryl type or other group without $\beta$-hydrogen.

The Heck-Mizoroki reactions under conventional conditions are usually performed in aprotic solvents like dimethylformamide (DMF), dimethylacetamide or dimethyl sulfoxide (DMSO) being the time and temperature used related with the reactivity of the halide. The bases usually used are $\mathrm{Et}_{3} \mathrm{~N}$, NaOAc or aqueous $\mathrm{Na}_{2} \mathrm{CO}_{3} \cdot{ }^{41,42}$

The catalysts (1-5 mol\%) used in the Heck reaction can be complexes of palladium(0) or palladium(II). The most common sources of palladium(0) used in this type of reaction can be phosphines complexes of $\operatorname{Pd}(0)$ like tetrakis(triphenylphosphine)palladium $(0) \quad\left[\mathrm{Pd}\left(\mathrm{PPh}_{3}\right)_{4}\right]$ or dibenzylidene-acetone complexes of $\operatorname{Pd}(0)$ such as $\operatorname{Pd}_{2}(\mathrm{dba})_{3}(\mathrm{dba}) .{ }^{43}$ The palladium(II) salts or complexes usually used to generate in situ palladium $(0)$ are $\mathrm{PdCl}_{2}, \quad \mathrm{Pd}(\mathrm{OAc})_{2}, \quad\left(\mathrm{PPh}_{3}\right)_{2} \mathrm{PdCl}_{2}$, $(\mathrm{PhCN})_{2} \mathrm{PdCl}_{2}$ or $\left(\mathrm{MeCN}_{2} \mathrm{PdCl}_{2}\right.$. The reduction of palladium(II) occurs in general in presence of amines, phosphines or alkenes. ${ }^{43}$ More recently, catalysts known as palladacycles have been developed and recognized as very efficient catalytic species in the activation of poor reactive 
halides. $^{43}$ The use of colloidal Pd solutions as catalyst precursors in Heck coupling was also described. It had been known for a long time that tetraalkylammonium halides stabilize nano-sized transition-metal colloids. ${ }^{44}$ The surfactants prevent undesired agglomeration by forming a monomolecular layer around the metal. ${ }^{45,46}$

The four main steps of the Heck catalytic cycle are presented in a simplified version in Fig. 3, being the main catalytic cycle initiated by the oxidative addition of the aryl halide to the $\operatorname{Pd}(0)$ species (i.), followed by insertion (ii.), beta elimination (iii.) and reductive elimination (iv.). ${ }^{42-44}$

The rate of oxidative addition with $\mathrm{C}_{\text {aryl }}$-halogen bonds increases according to the following order: $\mathrm{C}-\mathrm{F}<\mathrm{C}-\mathrm{Cl}<\mathrm{C}-$ $\mathrm{Br}<\mathrm{C}-\mathrm{I}$.

The Heck-Mizoroki reaction is one of the best methods to achieve substituted alkenes, dienes, and other unsaturated structures, many of which are important intermediates in the complex natural product synthesis, and in the production of fine chemicals. ${ }^{43-47}$

However, this reaction suffers from various limitations which hamper its potential for industrial exploitation. For instance the need of high amounts of palladium catalyst that is expensive is one of the technical limitations for the applicability of this reaction. Other important drawbacks are: i) the decomposition of conventional catalysts at high temperatures, ii) the high price of the most reactive reagents like iodides and triflates when compared with the more accessible chloroaromatics, iii) the recycle of the catalyst in order to avoid the loss of palladium catalyst at the end of the reaction and iv) the salt waste. ${ }^{42}$

In fact, the utilization of ILs in place of common solvents during the Heck-Mizoroki coupling is an example of the effort from the scientific community to work under environmental friendly conditions accompanied by an improvement in the catalytic efficiency.

\section{Heck-Mizoroki reaction in ammonium, imidazolium, pyridinium and phosphonium based ILs}

The first reference on the use of ILs as an alternative reaction medium to perform Heck-Mizoroki reactions under phosphine free conditions was reported in 1996 by Kauffmann and co-workers. ${ }^{48}$ The authors studied the efficiency of hexadecyltributylphosphonium bromide (hdtbpb), tetrabutylammonium bromide (tbab), and tetraoctylammonium bromide at

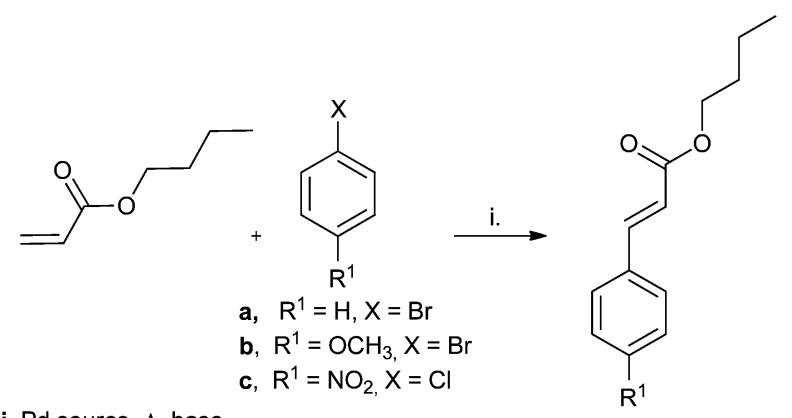

Scheme 1
$100{ }^{\circ} \mathrm{C}$ in the coupling of bromobenzene with butyl acrylate in the presence of different Pd sources (Scheme 1 and Table 1). The high substrate conversions and the high yields obtained for the trans- butyl cinnamate confirmed the high efficiency of these reaction mediums, independently of the catalyst. The addition of lithium bromide or sodium acetate was responsible for a considerable reduction on reaction times; it was verified that in the presence of hdtbpb, after the distillation of the product, the catalyst maintained the efficiency in the two following runs. These reaction mediums were also considered appropriated for running Heck-Mizoroki reactions between butyl acrylate and 4-chloronitrobenzene or 4-bromoanisole affording the expected products in yields of $\mathrm{ca} 50 \%$; however these catalytic conditions were not efficient for chlorobenzene.

Three years later, Earle's group ${ }^{49}$ described a detailed study based on the use of $N, N^{\prime}$-imidazolium and $N$-alkylpyridinium ILs with different counter-anions in the Heck-Mizoroki reaction of ethyl acrylate with iodobenzene (Scheme 2). The reactions were performed in the presence of $\mathrm{Pd}(\mathrm{OAc})_{2}$ as the catalyst precursor and $\mathrm{Et}_{3} \mathrm{~N}$ or $\mathrm{NaHCO}_{3}$ as the base. The efficiency of the coupling was compared in the presence of $N$-hexylpyridinium $\left[N-\mathrm{C}_{6} \mathrm{H}_{13} \mathrm{Py}\right]$ with different anions (chloride, hexafluorophosphate and tetrafluoroborate), $[\mathrm{bmim}]\left[\mathrm{PF}_{6}\right]$ and 1-pentyl-3-methylimidazolium [pmim] chloride as solvents.

In the experiments performed with the chloride salts and under identical reaction conditions, the trans-ethyl cinnamate was obtained in higher yields in the $N$-hexylpyridinium salt than in the imidazolium salt (Table 2). In the same study, the IL $\left[N-\mathrm{C}_{6} \mathrm{H}_{13} \mathrm{Py}\right]\left[\mathrm{BF}_{4}\right]$ showed to be more efficient than $\left[N-\mathrm{C}_{6} \mathrm{H}_{13} \mathrm{Py}\right]\left[\mathrm{PF}_{6}\right]$, but required higher reactions temperatures $\left(80{ }^{\circ} \mathrm{C}\right)$ and times $(72 \mathrm{~h})$ to attain the efficiency of the chloride analogue.

The low yields observed with imidazolium salts suggest that the presence of phosphine ligand or high temperature are required for a more efficient coupling. When the imidazolium salt $[\mathrm{bmim}]\left[\mathrm{PF}_{6}\right]$ was used, the presence of the phosphine ligand $\mathrm{Ph}_{3} \mathrm{P}$ was required to obtain the trans-ethyl cinnamate in high yield and it was referred that this system can be recycled six times without loss of catalyst activity; the product was extracted with hexane and the triethylammonium iodide salt with water.

The scope of this system was extended to the less reactive 4-bromoanisole where the effect of a range of ligands (Group 15) was studied at different temperatures allowing the establishment of conditions, where the product was obtained in yields, that exceed the ones obtained under classical conditions. In addition, the ILs $\left[N-\mathrm{C}_{6} \mathrm{H}_{13} \mathrm{Py}\right][\mathrm{Cl}]$ and [bmim $]\left[\mathrm{BF}_{4}\right]$ showed to be excellent reaction mediums in the reaction of benzoic anhydride (used as the source of the aryl moiety and where the presence of a base was not required) and butyl acrylate. The trans-butyl cinnamate was obtained in excellent yields (90-95\%) although higher reaction temperatures were required: $160{ }^{\circ} \mathrm{C}$ for $\left[N-\mathrm{C}_{6} \mathrm{H}_{13} \mathrm{Py}\right][\mathrm{Cl}]$ in the presence of $\mathrm{PdCl}_{2}$ and $200{ }^{\circ} \mathrm{C}$ for $[\mathrm{bmim}]\left[\mathrm{BF}_{4}\right]$ in the presence of $\mathrm{Pd}(\mathrm{OAc})_{2} 2 \mathrm{P}(o \text {-tol })_{3}$.

The authors suggested that the Heck-Mizoroki reactions performed in the IL $\left[N-\mathrm{C}_{6} \mathrm{H}_{13} \mathrm{Py}\right][\mathrm{Cl}]$ where the phosphine ligands hinder the reaction, a $\mathrm{Pd}(\mathrm{II}) / \mathrm{Pd}(\mathrm{IV})$ redox is probably involved. In the case of the imidazolium IL [pmim][Cl] it was 
Table 1 Selected data obtained on the effect of the Pd source in the Heck Mizoroki reaction of aryl halides with butyl acrylate in the presence of triethylamine as base $^{49}$

\begin{tabular}{|c|c|c|c|c|c|}
\hline $\mathrm{IL}$ & Aryl halide & Catalyst $1 \mathrm{~mol}(\%)$ & Time/h & Halide conversion & $\%$ of trans cinnamate \\
\hline \multirow[t]{6}{*}{ hdtbpb } & \multirow[t]{4}{*}{ bromobenzene } & $\mathrm{Cl}_{2} \mathrm{Pd}\left(\mathrm{PPh}_{3}\right)_{2}$ & 24 & $>99 \%$ & $>99$ \\
\hline & & $\mathrm{PdCl}_{2}$ & 16 & $84 \%$ & 81 \\
\hline & & $\mathrm{Pd}(\mathrm{OAc})_{2}, 1.5 \mathrm{~mol}$ equiv $\mathrm{NaOAc}$ & 17 & $>99 \%$ & 81 \\
\hline & & $\mathrm{Pd}(\mathrm{OAc})_{2}$ & 43 & $>99 \%$ & $>99$ \\
\hline & 4 bromoanisole & $\mathrm{Cl}_{2} \mathrm{Pd}\left(\mathrm{PPh}_{3}\right)_{2}$ & 16 & $>99 \%$ & 51 \\
\hline & 4 chloronitrobenzene & $\mathrm{Cl}_{2} \mathrm{Pd}\left(\mathrm{PPh}_{3}\right)_{2}$ & 16 & $97 \%$ & 52 \\
\hline \multirow[t]{2}{*}{ tbab } & bromobenzene & $\mathrm{Cl}_{2} \mathrm{Pd}\left(\mathrm{PPh}_{3}\right)_{2} 3.0 \mathrm{~mol}$ equiv $\mathrm{LiBr}$ & 6 & $95 \%$ & 90 \\
\hline & & $\mathrm{Cl}_{2} \mathrm{Pd}\left(\mathrm{PPh}_{3}\right)_{2}$ & 24 & $86 \%$ & 51 \\
\hline
\end{tabular}

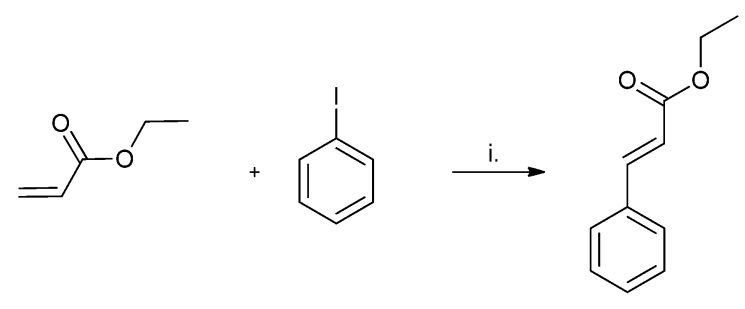

i. $\mathrm{Pd}(\mathrm{OAc})_{2} 2 \mathrm{~mol} \%$, base, ionic liquid $\left(\left[\mathrm{N}-\mathrm{C}_{6} \mathrm{H}_{13} \mathrm{Py}\right][\mathrm{X}]\right.$ or $[\mathrm{bmim}][\mathrm{X}]$ or [pmim $][X])$

Scheme 2

suggested the formation of carbenes (due to the acidic 2- $\mathrm{H}$ proton) in the presence of the base, that can act as ligands for Pd(II) to afford active catalyst species.

These two works were the first to evaluate the role of a variety of ILs as solvents in Heck-Misoroki reactions. In both works the authors showed that ILs are able to dissolve preferentially the palladium catalysts in a triphasic system (IL, water and organic solvent).

Another important contribution in this field was reported in 2000 by Böhm and Herrmann, ${ }^{50}$ that investigated the coupling of electron-poor chloroarenes with different mono- and disubstituted olefins in a variety of IL and different palladium sources. The establishment of the best protocol was studied in the formation of stilbene from chlorobenzene and styrene (Scheme 3) in the presence of simple (e.g. $\mathrm{PdCl}_{2}$ ) and more complex palladium sources such as the phospha-palladacycles catalysts 6 and 7 and the carbene-type catalysts 8-10 (Fig. 4). From the wide range of IL tested (imidazolium, ammonium and phosphonium salts) the tetraalkylammonium salts principally tbab showed a superior performance and it was found that the coupling of chloroarenes can be performed in the

Table 2 Selected data obtained on the effect of IL in the Heck Mizoroki reaction of ethyl acrylate and iodobenzene in $\mathrm{ILs}$, with $2 \mathrm{~mol} \%$ of $\mathrm{Pd}(\mathrm{OAc})_{2}{ }^{50}$

\begin{tabular}{lllll}
\hline IL & Base & Reaction $T /{ }^{\circ} \mathrm{C}$ & Time $/ \mathrm{h}$ & $\%$ of trans cinnamate \\
\hline$\left[N \mathrm{C}_{6} \mathrm{H}_{13} \mathrm{Py}\right][\mathrm{Cl}]$ & $\mathrm{Et}_{3} \mathrm{~N}$ & 40 & 24 & 99 \\
& $\mathrm{NaHCO}_{3}$ & 24 & 98 \\
{$[\mathrm{pmim}][\mathrm{Cl}]$} & $\mathrm{Et}_{3} \mathrm{~N}$ & 40 & 72 & 10 \\
& $\mathrm{NaHCO}_{3}$ & 80 & 24 & 19
\end{tabular}

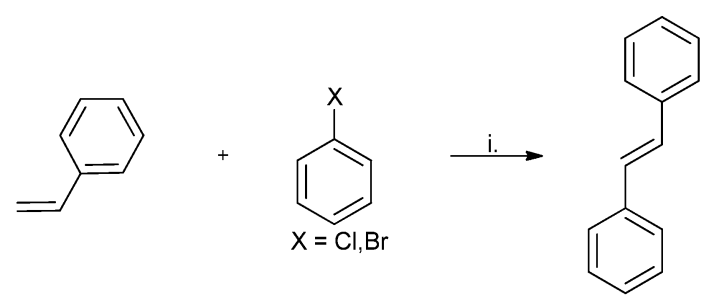

i. Pd source, base, $150^{\circ} \mathrm{C}$ and tbab or [bmim][Y], where $\mathrm{Y}=\mathrm{Br}^{-}$or $\mathrm{BF}_{4}^{-}$

Scheme 3

presence of less active catalysts such as palladium(II) dichloride and tetrakis(triphenylphosphane)-palladium(0).

Improvements in the coupling efficiencies when compared to the ones reported in molecular solvents were also reported. A survey on Heck-Mizoroki reactions in tbab involving other
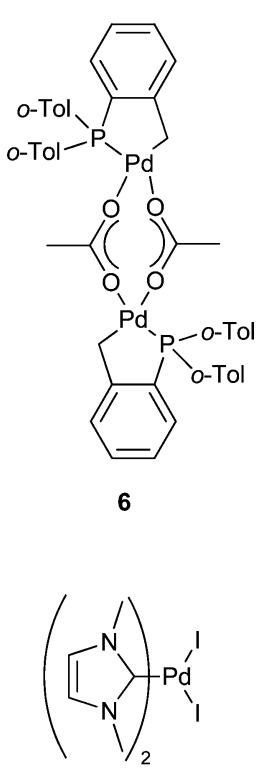

8<smiles>CC(C)(C)c1ccc(OP2(Oc3ccc(C(C)(C)C)cc3C(C)(C)C)(Oc3ccc(C(C)(C)C)cc3C(C)(C)C)Oc3c(C(C)(C)C)cc(C(C)(C)C)cc3P2(Cl)(Cl)Oc2ccc(C(C)(C)C)cc2C(C)(C)C)c(C(C)(C)C)c1</smiles><smiles>CC(C)CN1C=CN2CN3C=CN(CC(C)C)C3C(I)(I)C12</smiles><smiles>CC(c1ccccc1)N1C=CN(C(C)c2ccccc2)C1P(I)(I)(c1ccccc1)P(c1ccccc1)c1ccccc1</smiles>

10
Fig. 4 Phospha palladacycles and carbene type catalysts used in the formation of stilbene by Heck Mizoroki reaction. 
Table 3 Heck Mizoroki reaction involving butyl acrylate and aryl halides with $\mathrm{Pd}(\mathrm{OAc})_{2}$ in the presence of $[\mathrm{bmim}][\mathrm{Br}]$ or $[\mathrm{bmim}]\left[\mathrm{BF}_{4}\right]^{52}$

\begin{tabular}{lllll}
\hline $\mathrm{IL}$ & Aryl Halide & Reaction $T /{ }^{\circ} \mathrm{C}$ & Halide conversion/\% & $\%$ of trans cinnamate \\
\hline$[\mathrm{bmim}][\mathrm{Br}]$ & bromobenzene & 125 & 6 & 90 \\
& 4 bromobenzaldehyde & 100 & 88 & 97 \\
{$[\mathrm{bmim}]\left[\mathrm{BF}_{4}\right]$} & 4 bromoacetophenone & 110 & 90 & 98 \\
& bromobenzene & 125 & 26 & 82 \\
& 4 bromobenzaldehyde & 100 & 36 & 88
\end{tabular}

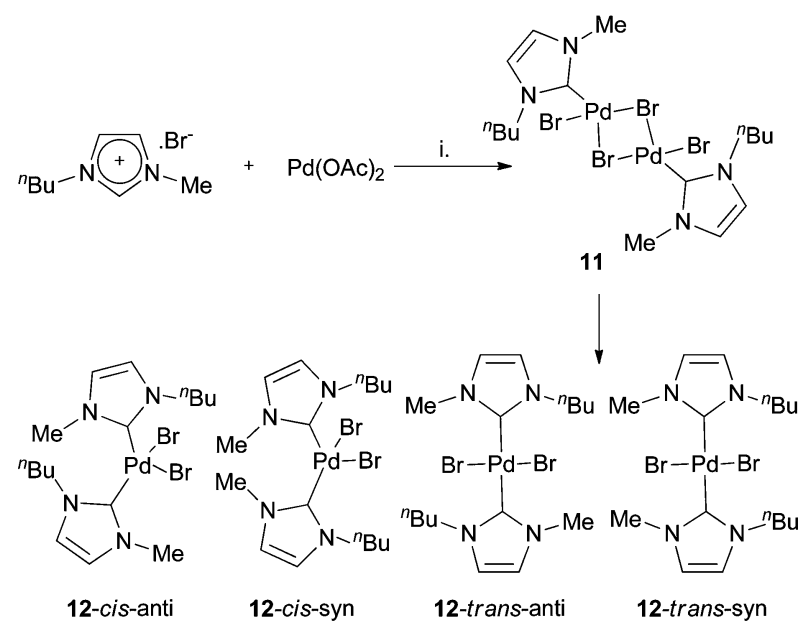

i. $\mathrm{NaOAc}, \mathrm{THF}, 45^{\circ} \mathrm{C}, 2 \mathrm{~h}$

\section{Scheme 4}

olefins and haloarenes (chloro-, bromo- and iodo-) or benzoic anhydride confirmed the scope of the protocol.

The efficiency of the recycle in tbab was tested in the coupling of bromobenzene with styrene either in the presence of $1 \mathrm{~mol} \%$ of $\mathrm{PdCl}_{2}$ or of catalyst $\mathbf{6}$; the reactants and the product were separated by distillation under vacuum $\left(130{ }^{\circ} \mathrm{C}\right.$, $10^{2} \mathrm{mbar}$ ) and no leaching of the catalyst was detected in the product. The higher number of recycles was found for catalyst 6, after 12 times no loss of activity was detected.

It was noted that, regardless of the conditions used, all of the imidazolium based ILs gave poor results $(22 \%$ for [bmim $]\left[\mathrm{BF}_{4}\right]$ and $13 \%$ for [bmim] $\left.[\mathrm{Br}]\right)$ in comparison to simple tbab salt (72\%) (Scheme 3). The results obtained suggest that the role of imidazolium based ILs is not very clear, affording in some cases the formation of Pd black, as it was observed with [bmim $]\left[\mathrm{BF}_{4}\right]$.

In 2000, Xiao and co-workers ${ }^{51}$ reported that the coupling of different aryl halides with acrylates was markedly more efficient when was performed in the IL $[\mathrm{bmim}][\mathrm{Br}]$ than in the analogous tetrafluoroborate salt ([bmim] $\left.]\left[\mathrm{BF}_{4}\right]\right)$ (Table 3).

It was found that the imidazolium ion is not innocent and reacts with the catalyst precursor affording the dimeric and monomeric $N$-heterocyclic carbene complexes $\mathbf{1 1}$ and $\mathbf{1 2}$ (Scheme 4) that were characterized by NMR, MS, and microanalysis.

The isolated trans-carbene complex 12 (Table 4) used in the olefination reaction of iodobenzene and 4-bromobenzaldehyde by ethyl or butyl acrylate in the presence of [bmim][Br], confirmed that $\mathbf{1 2}$ is the catalytically active complex, in the CC coupling.

The lower activity of carbene complex $\mathbf{1 2}$ observed in [bmim], but using as anion $\left[\mathrm{BF}_{4}\right]$, was justified by its transformation into less active species namely into inactive insoluble tetrakiscarbenes (Table 4). The catalytic activity for the Heck-Mizoroki reaction observed when $\mathrm{Pd}(\mathrm{OAc})_{2}$ was used, in the presence of $[\mathrm{bmim}]\left[\mathrm{BF}_{4}\right]$ (Table 3) was attributed by the authors to the formation of colloidal palladium particles from palladium decomposition.

Based on these conclusions other palladium- $N$-heterocyclic carbene complexes have been synthesized and tested in HeckMizoroki reactions, in the presence of ILs not only with the aim to develop new and recoverable palladium catalysts, but also to understand the role of the IL in the reaction mechanism (vide infra).

Xiao and co-workers ${ }^{37,52}$ also found that the imidazolium salt $[\mathrm{bmim}]\left[\mathrm{BF}_{4}\right]$ is an excellent medium to promote the ionic pathway in the arylation of electron-rich olefins without the resorting to halide scavengers, affording with high regioselectivity the $\alpha$ isomer (Scheme 5).

Table 4 Heck Mizoroki reactions catalyzed by the isolated carbene complex 12 in the presence of [bmim] $[\mathrm{Br}]$ or $[\mathrm{bmim}]\left[\mathrm{BF}_{4}\right]^{52}$

\begin{tabular}{lllll}
\hline $\mathrm{IL}$ & Aryl Halide & Reaction $T /{ }^{\circ} \mathrm{C}$ & Halide conversion $/ \%$ & $\%$ of trans cinnamate \\
\hline$[\mathrm{bmim}][\mathrm{Br}]$ & iodobenzene $^{a}$ & 90 & 94 & 99 \\
{$[\mathrm{bmim}]\left[\mathrm{BF}_{4}\right]$} & 4 bromobenzaldehyde $^{b}$ & 100 & 71 & 90 \\
& iodobenzene $^{a}$ & 90 & 35 & 56
\end{tabular}

${ }^{a}$ reaction with ethyl acrylate. ${ }^{b}$ reaction with butyl acrylate. 


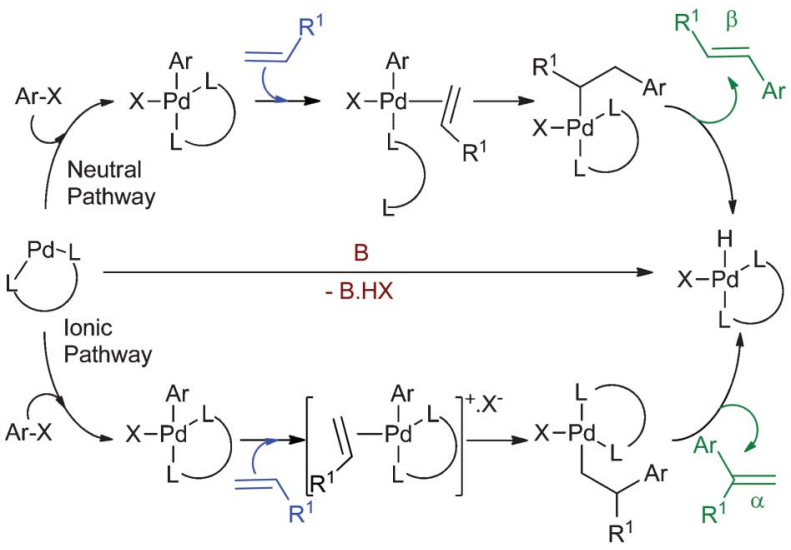

Scheme 5

The first studies involving the reaction of butyl vinyl ether with different aryl bromides showed that the best results (conversions higher than $99 \%$ and $\alpha / \beta$ regioselectivity $>99 / 1$ ) are obtained in the presence of $\mathrm{Pd}(\mathrm{OAc})_{2}$ and 1,3-bis(diphenylphosphino)-propane (DPPP) using triethylamine as base and [bmim] $\left[\mathrm{BF}_{4}\right]$ as solvent (Scheme 6). This protocol was also adapted with high success to the coupling of heteroaryl bromides (halopyridines, bromoquinoline and bromothiophenes) with different vinyl ethers and allyl alcohol. ${ }^{53,54}$ Although based on the same procedure excellent $\alpha$-regioselectivities were reported in Heck-Mizoroki reactions involving other electron-rich olefins such as allyltrimethylsilane ${ }^{53}$ and hydroxyalkyl vinyl ethers, ${ }^{55}$ the extension to enamides required the presence of DMSO as co-solvent (Scheme 7). ${ }^{53}$ These last conditions were also applied in the arylation of unsaturated alcohols. ${ }^{55}$ The work of the group considering this topic is the subject of a review in $2011 .^{56}$

Another important issue that was considered by several groups was the possibility of using chiral ionic liquids (CIL) to provide chiral compounds as non-racemic mixtures in HeckMizoroki couplings. Unfortunately the studies showed that the success is limited.

For instance, in the arylation of 2,3-dihydrofuran with iodobenzene catalysed by a chiral pyridinium IL with $\left[\mathrm{PdCl}_{4}{ }^{2}\right]$

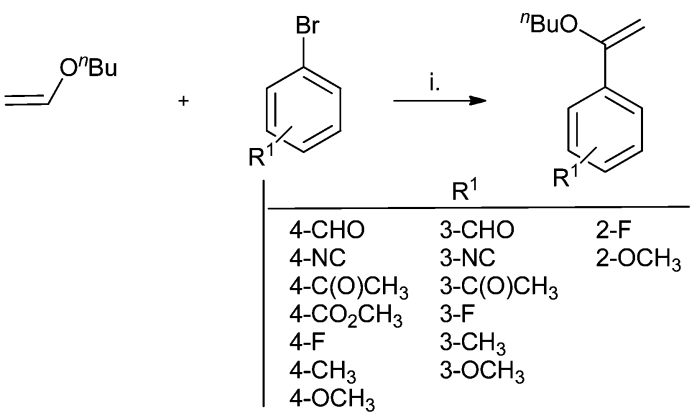

i. $2.5 \% \operatorname{Pd}(\mathrm{OAc})_{2}, 5 \%$ DPPP, 1.2 eq $\mathrm{Et}_{3} \mathrm{~N}$, [bmim] $\left[\mathrm{BF}_{4}\right], 115^{\circ} \mathrm{C}, 24 \mathrm{~h}$ or $36 \mathrm{~h}$

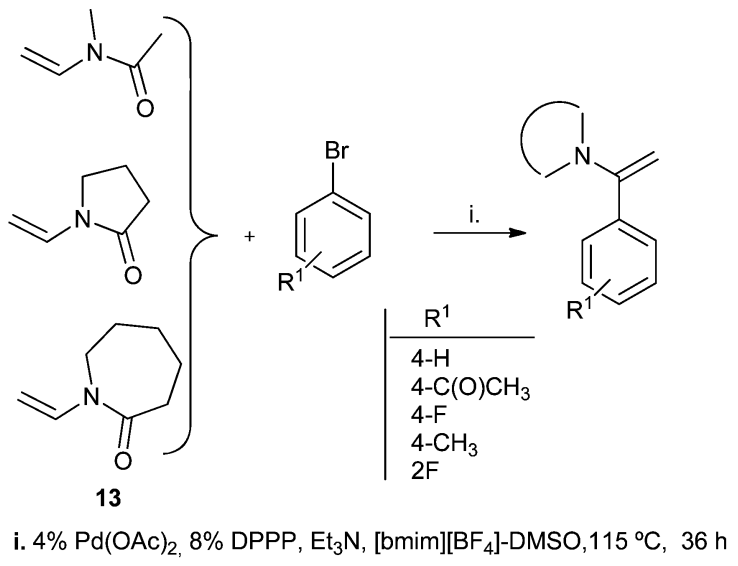

Scheme 7

14 in $[\mathrm{bmim}]\left[\mathrm{PF}_{6}\right]$ no enantiomeric excess was detected (Scheme 8). ${ }^{57}$

Also, in the arylation of aza-endocyclic acrylate $\mathbf{1 5}$ using arenediazonium salts $\mathbf{1 6}$ or aryl iodides in the presence of a series of chiral imidazolinium, imidazolium, pyridinium and nicotine-derived ILs no asymmetric induction was observed; however the coupling was effective leading to complete conversion of substrate and excellent yield of the HeckMizoroki adduct (Scheme 9). ${ }^{58}$ Another publication refer that the oxyarylation of 7-benzyloxy- $2 H$-chromene $\mathbf{1 7}$ in CILs 18 afforded the desirable product 19 with $5 \%$ e.e. (Scheme 10). ${ }^{59}$ Trzeciak and co-workers ${ }^{60}$ also studied the cross-coupling of iodobenzene with 2,3-dihydrofuran in the presence of ILs namely with those bearing chiral anions (Scheme 11). The authors highlighted the influence of IL anionic part on the reaction course where conversions from $0.4 \%$ to $100 \%$ were obtained depending on the counter-anion of the morpholinium salt used 23 (Fig. 5 and Table 5). In the presence of morpholinium salts $\mathbf{2 3}$ bearing chiral anions e.e. values up to $10 \%$ were attained. Considering the results obtained that are higher than the ones obtained when the chirality is in the cationic part, they considered that tuning the anionic part is probably more efficient than tuning the cationic part.

The group of Capretta ${ }^{61}$ considered also the possibility to perform Heck-Mizoroki couplings in thermally and chemically stable quaternary phosphonium salts. The authors selected trihexyl(tetradecyl)phosphonium (thp) as the cation and studied the effect of different counter anions (bromide,

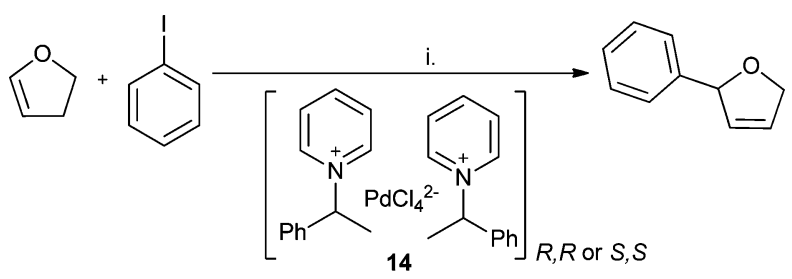

i. [bmim] $\left[\mathrm{PF}_{6}\right], \mathrm{Et}_{3} \mathrm{~N}, 100^{\circ} \mathrm{C}$ 


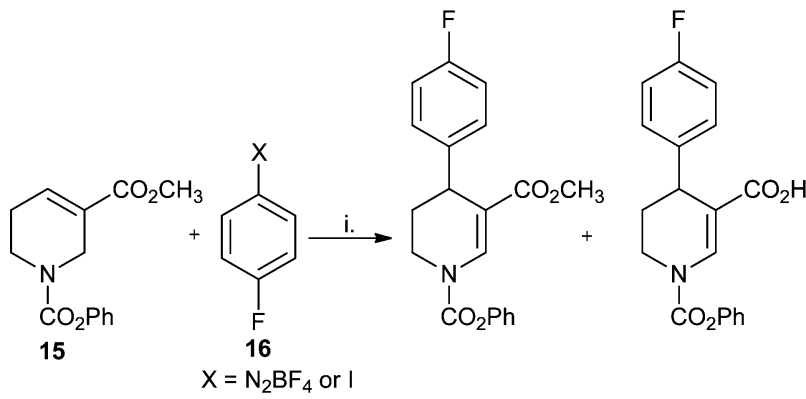

i. Pd source, $\mathrm{Ag}_{2} \mathrm{CO}_{3}, \Delta$, chiral ionic liquid (CIL)

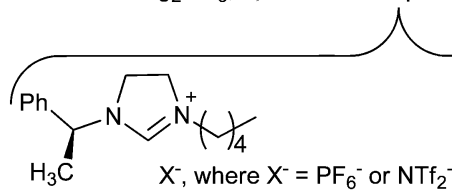

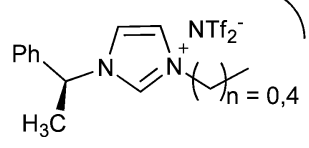<smiles>CC(c1ccccc1)[n+]1ccccc1</smiles><smiles></smiles><smiles>C[C@H](c1ccccc1)n1cc[n+](CC(C)(C)C)c1</smiles><smiles>Ic1ccccc1C=CC1C=[C+]C(c2ccccc2)O1</smiles>

i. $\mathrm{Pd}(\mathrm{OAC})_{2}, \mathrm{IL} / \mathrm{Pd}=20, \mathrm{DMF}, \mathrm{K}_{2} \mathrm{CO}_{3}$, mesitylene, $70^{\circ} \mathrm{C}, 2 \mathrm{~h}$

Scheme 11

containing the Pd catalyst was shown to be active and reusable at least three times.

The possibility that palladium nanoparticles can be formed under different experimental conditions and can be the reservoir of the Pd active species in Heck transformations was suggested by a high number of studies. ${ }^{62}$ For example, Calò and co-workers pointed out that Pd nanoparticles easily prepared just by adding palladium acetate to a mixture of tbab in the presence of tetrabutylammonium acetate (tbaa) as the base are highly efficient in the coupling of a wide range of olefins and aryl halides, namely aryl chlorides. ${ }^{63-66}$ This work has been the subject of an excellent review by the authors. ${ }^{44}$

Another important contribution concerning the role of palladium nanoparticles in Heck reactions in IL is due to Dupont, where it was demonstrated that imidazolium ionic liquids can be used to investigate the shape and size of colloidal nanoparticles. ${ }^{67}$ The authors suggested based on TEM and ICP-MS results that the aryl halide oxidative addition coupling of iodobenzene and methyl acrylate. The screening was performed using $\mathrm{Pd}_{2} \mathrm{dba}_{3} \cdot \mathrm{CHCl}_{3}$ as the catalyst and triethylamine as the base and the results showed that the counter anion plays a significant role in the outcome of the reaction. The best conversions were obtained with thpdecanoate and thp-Cl (75\% and 78\% respectively) but thp-Cl demonstrated to be much easier to work in the purification process. Further optimization of the experimental conditions where different Pd sources and bases were considered revealed that the combination of $\mathrm{Pd}(\mathrm{OAc})_{2}$ with sodium acetate and water afforded at $50{ }^{\circ} \mathrm{C}$ and after $2 \mathrm{~h}$ excellent yields in the products obtained from a series of aryl iodides and olefins; for the aryl bromides the authors referred that triethylamine showed to be the best choice and high temperature $\left(100{ }^{\circ} \mathrm{C}\right)$ and reaction times $(4 \mathrm{~h})$ were required for a most efficient coupling $(>80 \%)$. In all the transformations a complete regioselectivity for the $\beta$-position was observed and no cisolefin products were detected. In addition, the IL layer

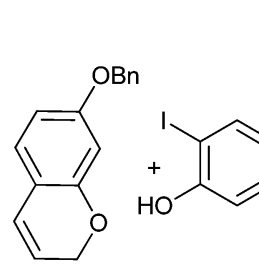

17

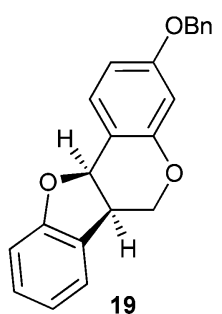

18

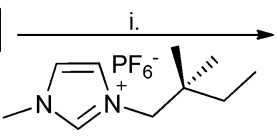

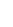

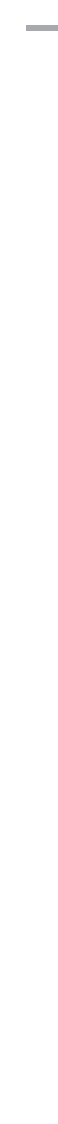

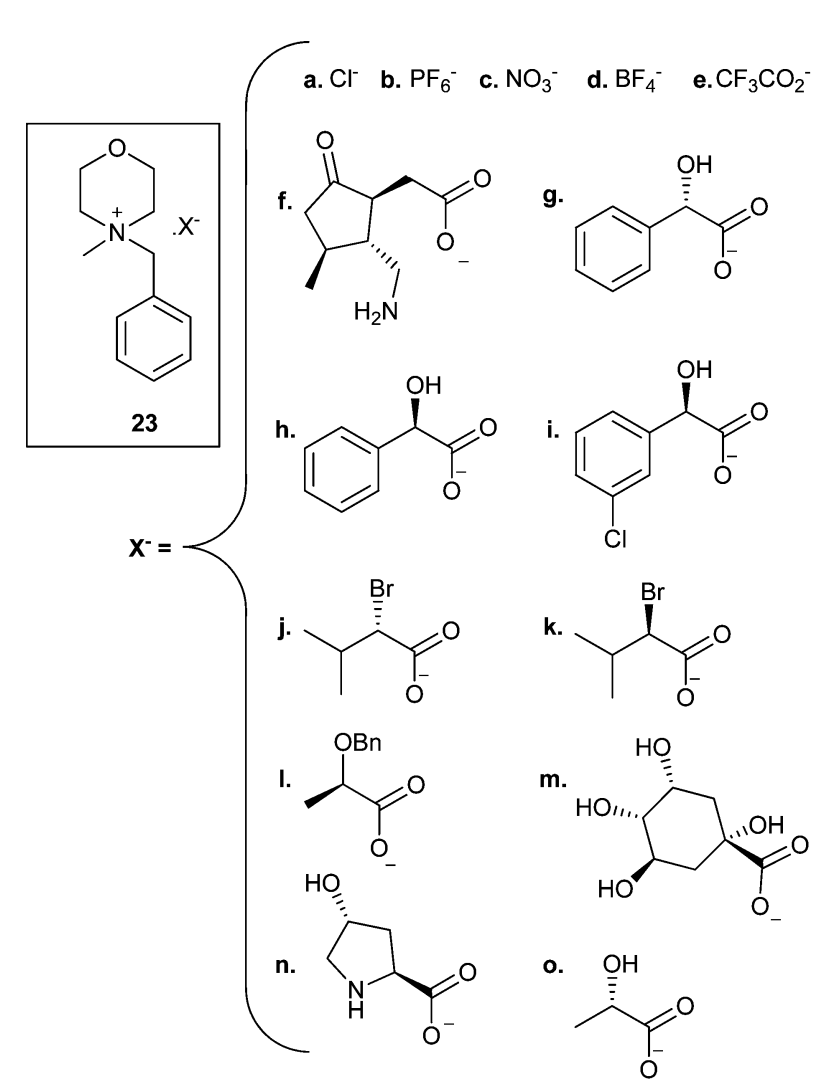

Fig. 5 Morpholinium ILs salts. 
Table 5 Heck Mizoroki reaction in DMF of 2,3 dihydrofuran with aryl halides catalyzed by $\operatorname{Pd}(\mathrm{OAc})_{2}$ in the presence of morpholinium salts $\mathbf{2 3}$

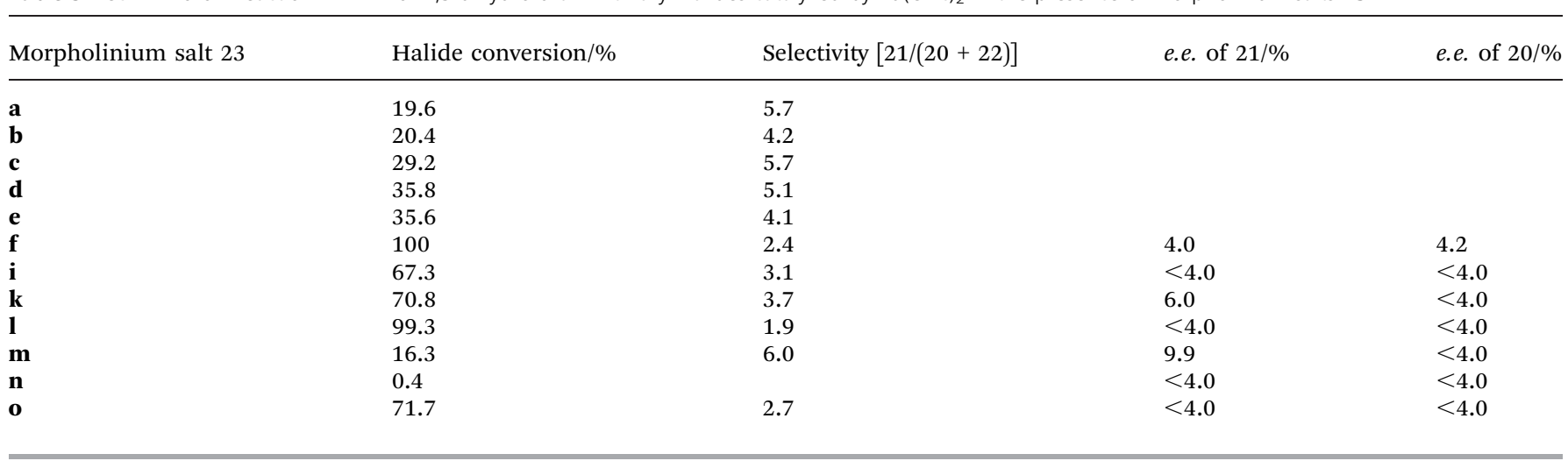

occurs onto the metal surface. This step is followed by cleavage of the oxidized molecular species which then enters in the main catalytical cycle. The $\operatorname{Pd}(0)$ formed can continue in the cycle or to go back to the nanoparticle pool.

Based on their previous results ${ }^{44,65,68-70}$ that Pd colloids can promote the $\mathrm{C}-\mathrm{Cl}$ activation, Nacci et $a .^{71}$ reported the use of Pd nanoparticles obtained in ILs and water as catalysts in onepot sequential Heck-Mizoroki and Suzuki coupling reactions using bromo-chloroarenes or bromo-iodo-chloroarenes. The strategy allowed to prepare extended $\pi$-systems having a multisubstituted arene with different motifs as the basic skeleton.

Authors examined the one-pot double Heck-Mizoroki olefination of 1,2-, 1,3- and 1,4-bromochlorobenzene isomers with an array of olefins (Scheme 12). The reaction conditions were adjusted to process first $0.5 \mathrm{mmol}$ of both the dihalide and alkene using a molten mixture of tbab as solvent and tbaa as base, in the presence of $\mathrm{Pd}(\mathrm{OAc})_{2}$ as the catalyst source.

By a careful selection of the temperature, the coupling at the more reactive bromine site of the dihalide occurred within 0.5-1 $\mathrm{h}$, with the formation of only trace amounts of the symmetric double coupled product. The second olefination was initiated immediately after the end of the previous one, by addition of the second olefin and was performed at $120{ }^{\circ} \mathrm{C}$ or $140{ }^{\circ} \mathrm{C}$ depending on the haloarene. The yields of the unsymmetrical arenes obtained with this protocol were really comfortable and varied between $52 \%$ and $87 \%$ depending on the bulkiness of the arene and of the olefin.

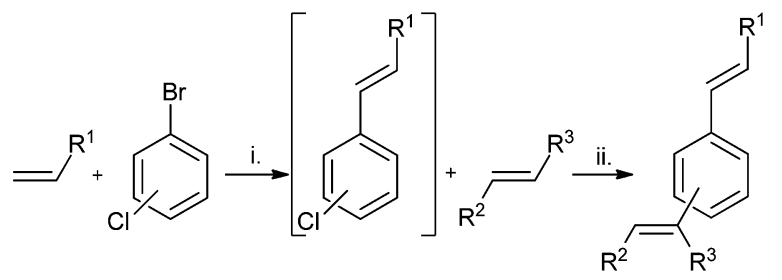

i. Pd nanoparticles, tbab/tbaa, $100^{\circ} \mathrm{C}$ ii. $120^{\circ} \mathrm{C}$
The extension of this highly sustainable protocol due to the use green solvents (ILs or water), ligand-free (no toxic or expensive phospane ligands), relatively mild conditions to the combination of Heck-Mizoroki with Suzuki coupling was also considered by the authors.

Recently, Shi et al. ${ }^{72}$ developed a heterogeneous catalytic system based on the coordination of $\mathrm{PdCl}_{2}$ with the IL $\mathbf{2 4}$ immobilized in $\mathrm{SiO}_{2}$ supporter (Scheme 13). The authors referred that parts of [Cl ] is coordinated with $\mathrm{PdCl}_{2}$ and the catalytical centre was transferred to the heterogeneous support, while unreacted [Cl ] and imidazolium cation can play the trait of the homogeneous reaction of the IL in the Heck-Mizoroki reaction. This $\mathrm{PdCl}_{2}$-IL brush assembly showed to be efficient for coupling of a wide range aryl iodides, even water insoluble ones with different acrylic acids in water, under aerobic conditions and in the absence of an organic co-solvent or any other additives. The catalyst was easily recovered by filtration and was reused eight times with losing efficiency. The authors considered that due to its

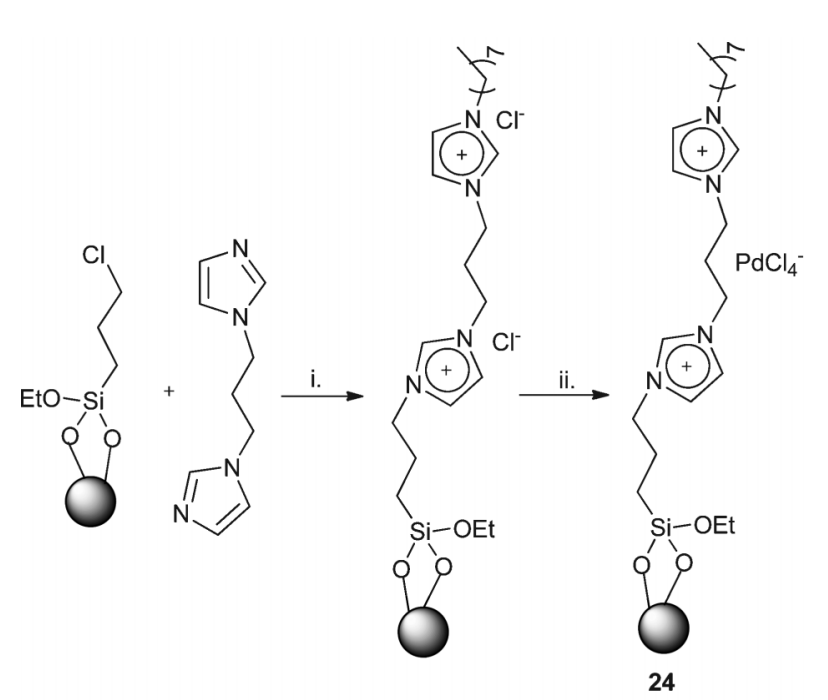

i. toluene, reflux, $48 \mathrm{~h}$ followed by $\mathrm{C}_{8} \mathrm{H}_{17} \mathrm{Cl}$, toluene, reflux, $24 \mathrm{~h}$

ii. $\mathrm{PdCl}_{2}, \mathrm{CH}_{3} \mathrm{CN}$, reflux 
<smiles>CC(=O)c1ccc(O)cc1C=Cc1ccc(O)cc1/C(C)=N\O</smiles><smiles>C/C(=N/O)c1ccc(OCCCCCBr)cc1</smiles>

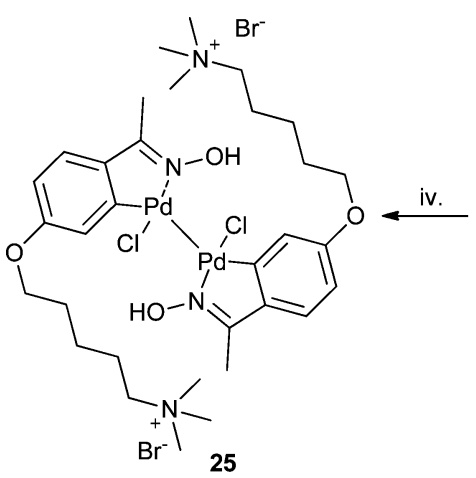<smiles></smiles>

i. $\mathrm{NH}_{2} \mathrm{OH}, \mathrm{NaOAc}, \mathrm{H}_{2} \mathrm{O}$, reflux, $1 \mathrm{~h}$ ii. 1,5 dibromopentane, $\mathrm{K}_{2} \mathrm{CO}_{3}$ acetone, reflux, $48 \mathrm{~h}$ iii. $\mathrm{Na}_{2} \mathrm{PdCl}_{4}, \mathrm{NaOAc}, \mathrm{CH}_{3} \mathrm{OH}, 72 \mathrm{~h}$ iv. $\mathrm{N}\left(\mathrm{CH}_{3}\right)_{3}, \mathrm{THF}, 50^{\circ} \mathrm{C}, 36 \mathrm{~h}$

Scheme 14

recyclability and the use of neat water as the reaction medium make it distinguished by both green and economic advantages from other palladium-based catalysts.

Singh and co-workers ${ }^{73}$ reported the preparation of the ammonium tagged oxime carbapalladacycle 25 (Scheme 14) and its intercalation by ion-exchange method in $\mathrm{Na}^{+}-\mathrm{MMT}$ (montmorillonite) clay. The results show that carbapalladacycle 25 under homogeneous and heterogeneous system promote Heck-Mizoroki couplings efficiently and with good recyclability.

\section{Heck-Mizoroki reaction in ILs catalyzed by $N$-heterocyclic carbene complexes}

Metal complexes of $N$-heterocyclic carbenes (NHCs) have been reported as a class of moisture, air and thermally stable catalysts with remarkable activity towards carbon-carbon bond forming reactions such as the Heck-Mizoroki and Suzuki coupling reactions. ${ }^{74}$

The NHCs due to their strong $\sigma$-donating and weak $\pi$-acids character are normally comparable to $\mathrm{P}-, \mathrm{N}$ - or $\mathrm{O}$-donating ligands and have been able to challenge the widely used tertiary phosphines. ${ }^{75}$

These NHCs ligands are usually prepared via deprotonation of the corresponding azolium salts (imidazolium, triazolium, tetrazolium, pyrazolium, benzimidazolium, oxazolium, thia-

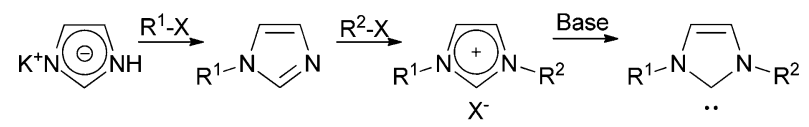
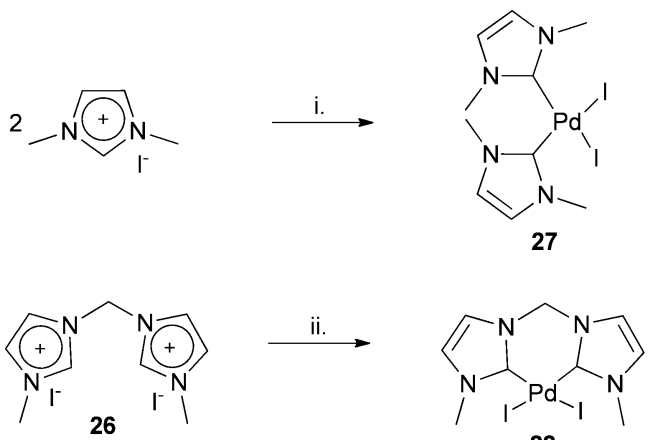

28

i. $\mathrm{PdOAc}_{2}, \mathrm{THF}$, reflux, $30 \mathrm{~min}$

ii. $\mathrm{PdOAc}_{2}, 170^{\circ} \mathrm{C}, 5 \mathrm{~min}$

Scheme 16

zolium salts), as is exemplified in Scheme 15 for imidazole, by far the most used one.

The possibility of using NHC complexes as catalysts in Heck-Mizoroki reactions under free phosphine ligands was considered in 1995 by Herrmann and co-workers. ${ }^{76}$ The group reported the synthesis of complexes 27 and 28 (70 and 40\% yield, respectively) by reaction of $\mathrm{Pd}(\mathrm{OAc})_{2}$ with the adequate iodides, the dimethylimidazolium and the diimidazolium 26 (Scheme 16).

The authors studied the efficiency of both complexes in Heck-Mizoroki coupling reactions using a series of aryl halides and butyl acrylate and verified that the conversion of 4-chloronitrobenzene and 4-chlorobenzaldehyde proceed quantitatively in the presence of complex 27 only with the addition of IL tbab (Scheme 17).

In the same context, Welton and co-workers ${ }^{77}$ demonstrated that the reaction of $\mathrm{Pd}\left(\mathrm{PPh}_{3}\right)_{4}$ with $\mathrm{ArBr}$ in the presence of [bmim $]\left[\mathrm{BF}_{4}\right]$ and $\mathrm{NaCl}$ (path $B$ ), or from reaction of $\mathrm{PdCl}_{2}$ with triphenylphosphine in the presence of $\left[\mathrm{bmim}^{2}\left[\mathrm{BF}_{4}\right]\right.$ (path A) afforded the NHC palladium 29 (Scheme 18).

The possibility of using carbene catalysts for the HeckMizoroki coupling of aryl chlorides in ILs was considered in 2002 by Beller and co-workers. ${ }^{78}$ The authors prepared several well-defined palladium(0) carbene complexes and found that
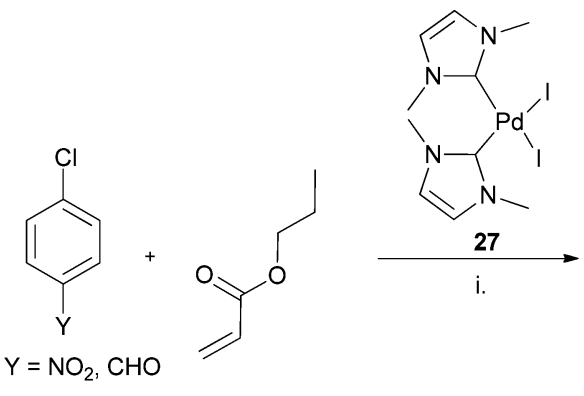

i. $N, N^{\prime}$-dimethylacetamide, $\mathrm{NaOAc}, 140^{\circ} \mathrm{C}$, tbab<smiles>[X]c1ccc(/C=C/C(=O)OCCCC)cc1</smiles> 


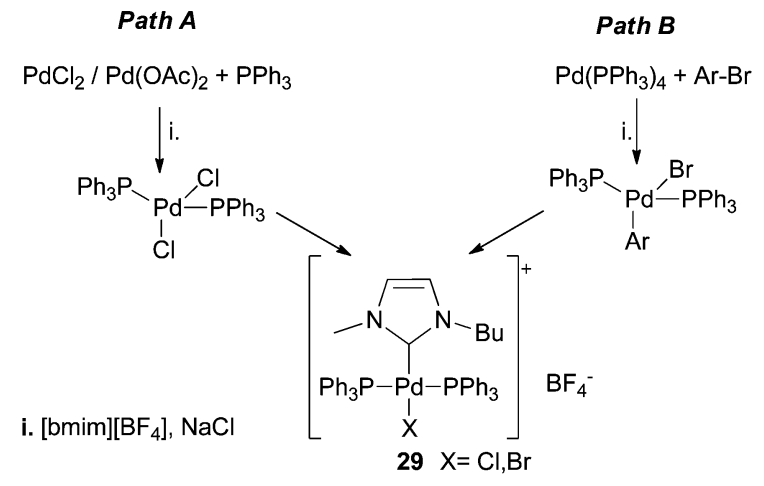

Scheme 18

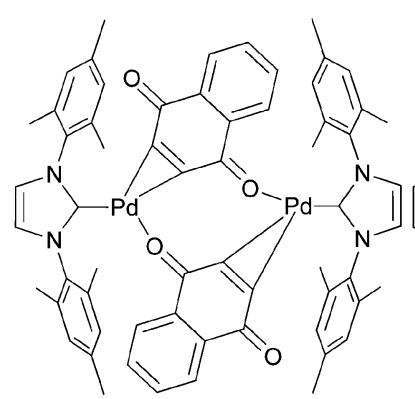

30

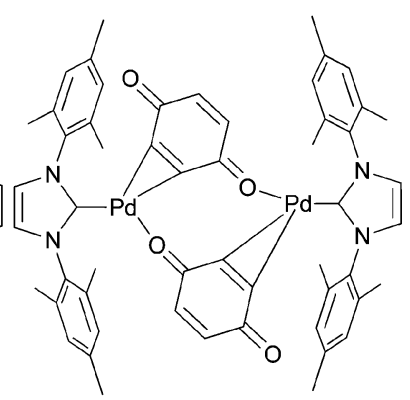

31
Fig. 6 Palladium(0) carbene complexes.

in tbab at $140{ }^{\circ} \mathrm{C}$, complex 30 and the analogue 31 with quinones (Fig. 6) are efficient catalysts in reactions of activated and non-activated aryl chlorides with styrene or 2-ethylhexyl acrylate, affording the corresponding stilbenes and cinnamic esters in good to excellent yields.

Shao and co-workers ${ }^{79}$ reported that the well-defined and easily accessible NHC-palladium(II)-1-methylimidazole complex 32 is an effective catalyst for reactions involving a variety of activated and deactivated aryl chlorides and styrenes if the

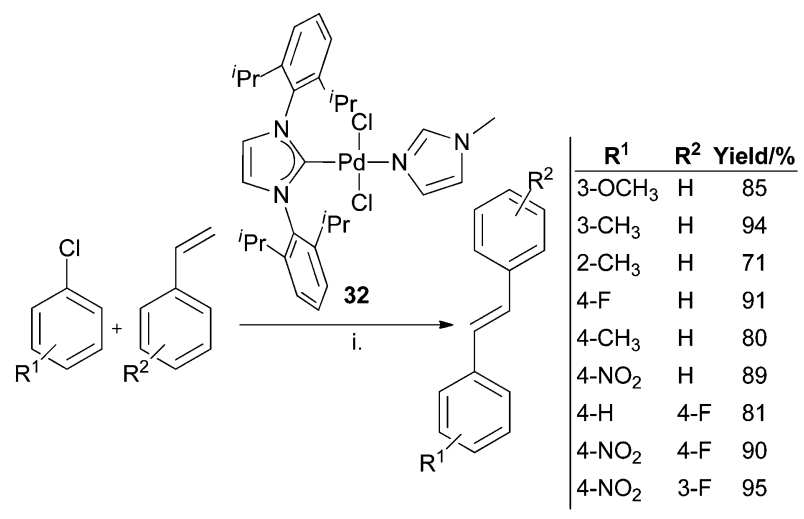

i. $1.0 \mathrm{~mol} \%$ of 32,2 equiv. $\mathrm{Cs}_{2} \mathrm{CO}_{3}$, tbab, $140^{\circ} \mathrm{C}$, air, $12 \mathrm{~h}$

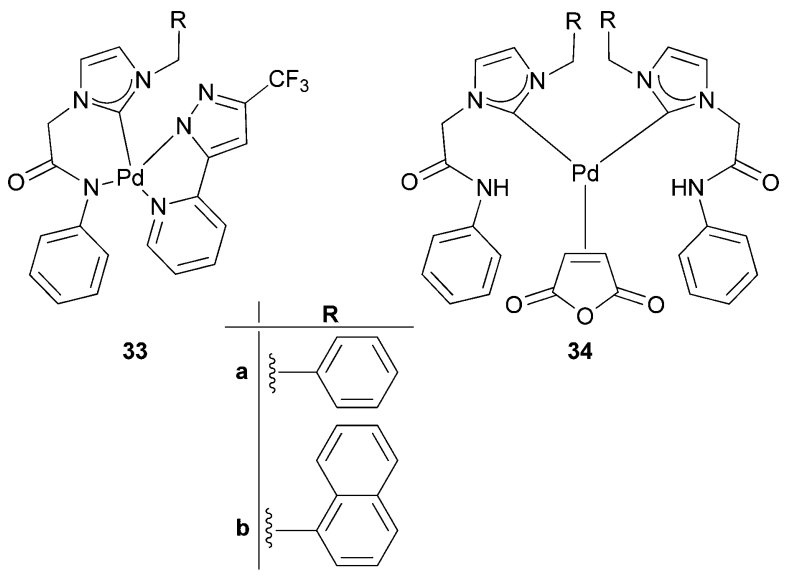

Fig. 7 Palladium complexes bearing NHC and amide functionalities.

reaction is performed in tbab (Scheme 19); under conventional solvent conditions the desired product was obtained in a very poor yield. The optimized conditions allowed to select $\mathrm{Cs}_{2} \mathrm{CO}_{3}$ as the best base for the coupling. Complex 32 can be easily prepared from commercially available $\mathrm{PdCl}_{2}$ and 1,3-bis(2,6diisopropylphenyl)imidazolium chloride.

In Fig. 7 are the structure of other palladium complexes bearing NHC and amide functionalities that showed also to be effective catalysts for reactions involving aryl chlorides and electron poor alkenes. ${ }^{80,81}$

The possibility of using NHC-Pd complexes immobilized on silica nanoparticles as catalysts in Heck-Mizoroki reactions was considered by Sen and Tandukar. ${ }^{82}$ The synthetic strategy to obtain the immobilized NHC ligand (Scheme 20) involved after the alkylation of imidazole with decyl bromide, the quaternization with neat chloropropyl triethoxysilane. Then, the resulting clear viscous IL 1-decyl-3-(triethoxysilylpropyl)imidazolium chloride (35) was covalently linked to nano-sized silica support by condensation with surface silanol groups.

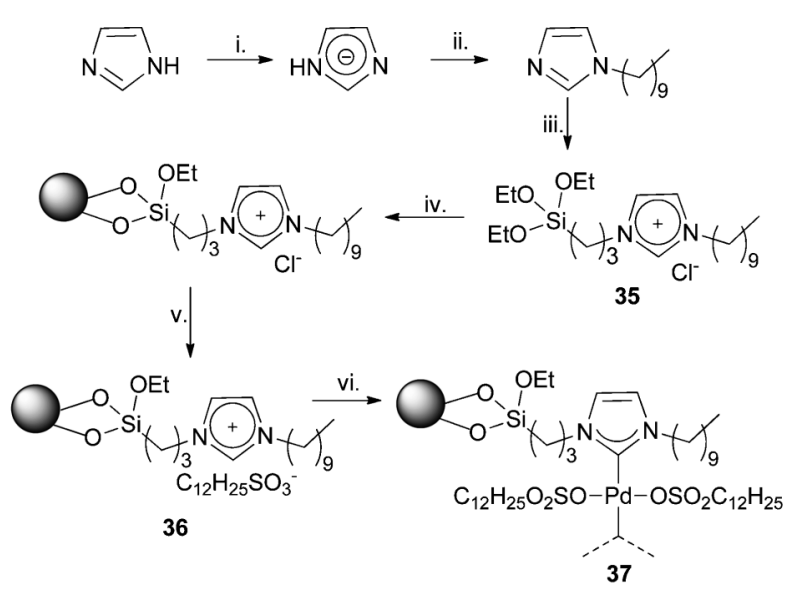

i. $\mathrm{Na}, \mathrm{THF}, 1 \mathrm{~h}$; ii. $\mathrm{C}_{10} \mathrm{H}_{21} \mathrm{Br}$,rt, $24 \mathrm{~h}$; iii. $\left(\mathrm{CH}_{3} \mathrm{CH}_{2} \mathrm{O}\right)_{3} \mathrm{Si}\left(\mathrm{CH}_{2}\right)_{3} \mathrm{Cl}, 105^{\circ} \mathrm{C}, 24 \mathrm{~h}$ iv. Colloidal $\mathrm{SiO}_{2}, \mathrm{H}_{2} \mathrm{O}, \mathrm{CH}_{3} \mathrm{OH}$; v. $\mathrm{NaC}_{12} \mathrm{H}_{25} \mathrm{SO}_{3}$; vi. $\mathrm{Pd}(\mathrm{OAc})_{2}$, toluene, 50 ${ }^{\circ} \mathrm{C}, 8 \mathrm{~h}$ 


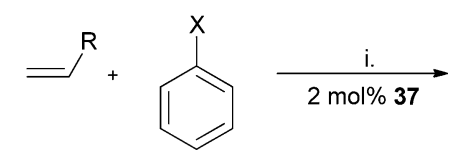

i. $\mathrm{N}(\mathrm{Et})_{3},[\mathrm{bmim}][\mathrm{Br}], 100^{\circ} \mathrm{C}$

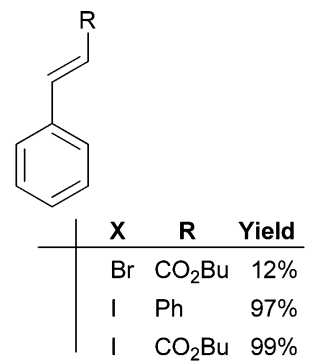

Scheme 21
The chloride ions were subsequently replaced by dodecane sulfonate ions. The NHC-Pd catalyst 37 was obtained by heating the silica supported $\mathrm{NHC}(\mathbf{3 6})$ with $\mathrm{Pd}(\mathrm{OAc})_{2}$ in toluene, at $50{ }^{\circ} \mathrm{C}$, for $8 \mathrm{~h}$.

The ability of the nanoparticle-bound palladium species to catalyze Heck-Mizoroki coupling was examined using phenyl iodides and bromides and the electron poor olefins butyl acrylate and styrene (Scheme 21). The reaction was performed at $100{ }^{\circ} \mathrm{C}$ using $[\mathrm{bmim}][\mathrm{Br}]$ as solvent and the best results were obtained with iodobenzene. The products were extracted with ether.

The reusability of the silica supported complex 37 was checked, but the product yield decreased to $19 \%$ in the second cycle.

Luis et $a .^{83}$ explored different strategies to introduce multiple imidazolium subunits in PS-DVB polymers (commercial Merrifield resins) able to form NHC-palladium complexes. The inclusion of other onium groups such as ammonium, pyridinium or 2-methylimidazolium not being able to form NHC IL were also considered. In Scheme 22 are the structure and the synthetic strategy envisaged to obtain one of those ligands tested in Heck-Mizoroki coupling of iodobenzene and methyl acrylate. The results obtained were particularly gratify-
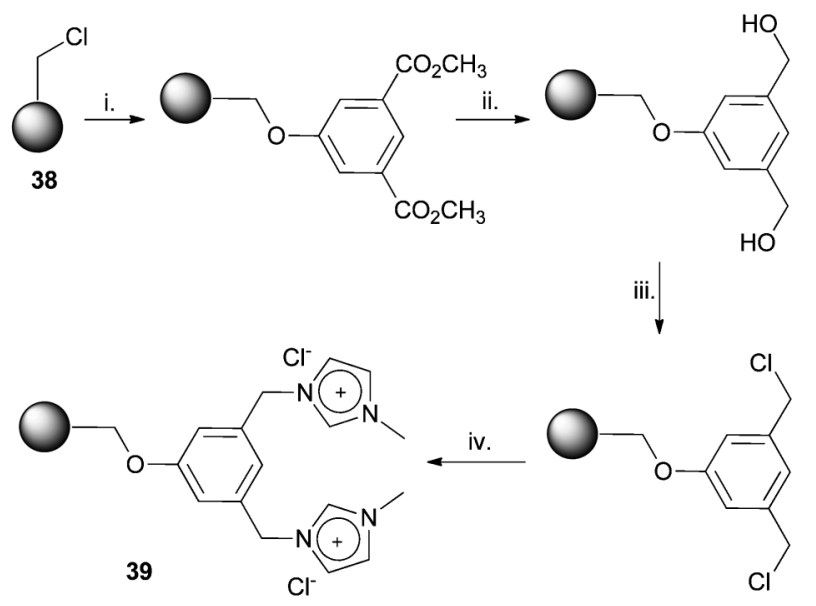

i. dimethyl-5-hydroxyisophtalate, acetone, $18 \mathrm{C} 6, \mathrm{~K}_{2} \mathrm{CO}_{3}, 12 \mathrm{~h}$, reflux; ii. $\mathrm{Li}\left(\mathrm{BH}_{4}\right), \mathrm{B}(\mathrm{OMe})_{3}, \mathrm{THF}, \mathrm{N}_{2}, 24 \mathrm{~h}$ reflux; iii. $\mathrm{SOCl}_{2}, \mathrm{CH}_{2} \mathrm{Cl}_{2}$, reflux, $4 \mathrm{~h}$; iv. 1-methylimidazolium, $80^{\circ} \mathrm{C}, 2 \mathrm{~h}$

Scheme 22

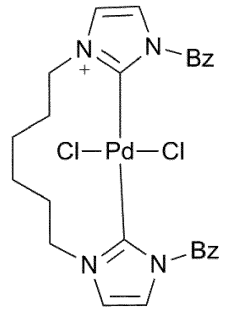

40

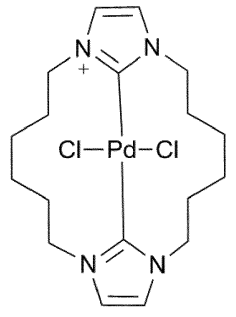

41<smiles>C[n+]1ccn(C(=O)c2ccccc2)c1[Pb](Cl)(Cl)c1n(C(=O)c2ccccc2)cc[n+]1C</smiles>

42

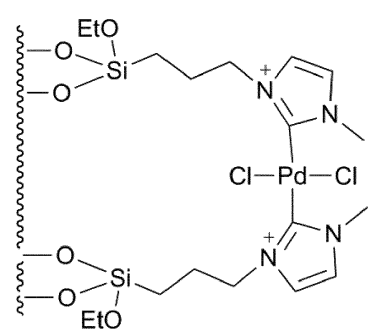

43

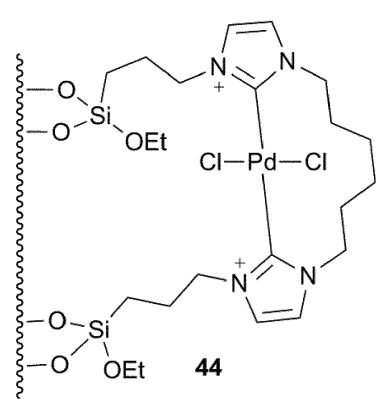

Fig. 8 Representation of $\mathrm{Pd}(॥)$ dicarbene complexes grafted and non grafted to hierarchical ZSM 5.

ing considering the recycling capacity of NHC-Pd complex based on ligand $\mathbf{3 9}$ obtained from resin $\mathbf{3 8}$ containing just two ditopic groups, that after several cycles did not show signs of deactivation.

Srivastava and co-workers ${ }^{84}$ described the synthesis and the catalytic activity of the $\mathrm{Pd}(\mathrm{II})$ dicarbene complexes $\mathbf{4 0}, \mathbf{4 1}$ and 42, based on imidazole and also of complexes 43 and 44 grafted in hierarchical ZSM-5 (Fig. 8). The acyclic Pd complex 40 and 42 were found to be more active (yields of $c a 90 \%$ or higher) than the cyclic one $\mathbf{4 1}$ ( $\mathrm{ca} 40 \%$ ) in the coupling of bromobenzene with styrene or methyl acrylate using DMF, at $143{ }^{\circ} \mathrm{C}$, in the presence of $\mathrm{K}_{2} \mathrm{CO}_{3}$. This feature was explained based on theoretical studies to a more difficult accessibility of the reagents in the cyclic $\mathbf{4 1}$.

Considering the heterogeneous carbenes the hierarchical $\mathbf{4 4}$ showed higher catalytic activity than $\mathbf{4 3}$ (ca $80 \%$ versus $53 \%$ ) in the coupling of the same substrates, that was justified due to the less amount of Pd present with this ligand. The hierarchical 44 exhibited high stability and showed negligible loss in activity even after five cycles. Unfortunately, the high dissociation energy of chlorobenzene compared to bromobenzene can explain the bad performance of the catalytic system, when the chloride was used.

From the results presented above can be affirmed that the NHC can be used as ligands and also to be supported and recycled in catalytic process. On the other hand the activation of the $\mathrm{C}(2)-\mathrm{H}$ of the imidazolium is not passive, the NHC are active species in the Heck-Mizoroki catalytical cycle.

\section{Heck-Mizoroki reaction in the third generation of ILs: Task specific ionic liquids (TSILs)}

On the base of the data reported in the above sections it is possible to conclude that the Heck-Mizoroki reaction based on the use of common ILs is clearly advantageous from the 


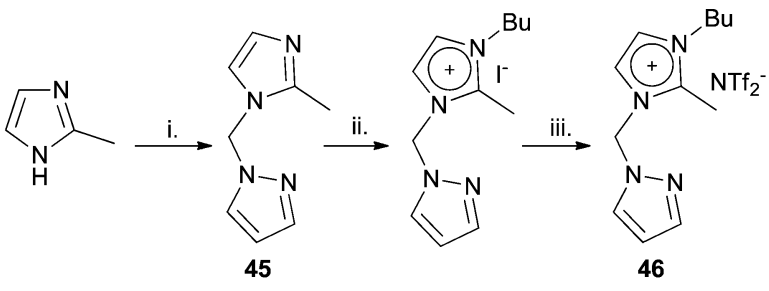

i. DMF, NaH,1-(chloromethyl)pyrazole hydrochloride, $1 \mathrm{~h}$; ii. Butyl iodide; iii. LiNTf

Scheme 23

point of view of product separation and re-use of the catalytic system.

However, common ILs still have a tendency to leach dissolved catalyst into the co-solvent used to extract the product. To avoid metallic catalysts leaching, significant changes have been made in ILs, namely by insertion of functional groups ${ }^{14,85-90}$ such as amine, amide, nitrile, pyrazole, alcohol, alkene, urea or thiourea affording the socalled task specific ionic liquids (TSILs).

The incorporation of those functional groups in the structure of ILs increases the solubility of the catalyst and decreases the chance of leaching. The recovery and reuse of the catalyst becomes more effective and the catalysts can be used in more cycles. ${ }^{89,90}$

These TSILs are able to coordinate with metals and consequently can act as catalyst ligand, as immobilization solvents and protective agents. ${ }^{91,92}$

The first TSIL used in the Heck-Mizoroki reaction was the pyrazolyl-functionalized imidazolium IL $\mathbf{4 6}$ reported by Shreeve in 2006. ${ }^{93}$ The authors selected this IL from a series of pyrazolyl- and 3,5-dimethylpyrazolyl-functionalized 2-methylimidazolium-based salts that were easily prepared from 2-methylimidazole. The synthetic approach for IL $\mathbf{4 6}$ involved the alkylation with 1-(chloromethyl)pyrazole hydrochloride of the deprotonated 2-methylimidazole in DMF followed by the quaternization of 1-pyrazolylmethylene-2methylimidazole (45) with butyl iodide and finally metathetic exchange of anion with $\operatorname{LiNTf}_{2}$ (Scheme 23).

The reaction of the salt with $\mathrm{PdCl}_{2}$ in methanol afforded the mononuclear palladium IL complex 47 (Scheme 24). The catalytic activity and the recyclability of this palladium complex in the corresponding IL was tested in the coupling of butyl acrylate with electron-rich iodides like 4-iodotoluene and 4-iodoanisole, as well as, electron-deficient ones 1-iodo-4nitrobenzene and 1-fluoro-4-iodobenzene (Scheme 24).

The corresponding butyl trans-cinnamates were obtained in high yields $(>84 \%)$ with complete regioselectivity at the $\beta$-position, after two hours. In addition, no cis coupled products were observed.

All the coupled products were easily separated from the catalytic solution by simple extraction with ether and hexane. After extracting the products, the resulting solution was washed with water to remove the ammonium salts and dried under vacuum for the next cycle. In the process, no apparent leaching of palladium species was observed. The catalytic

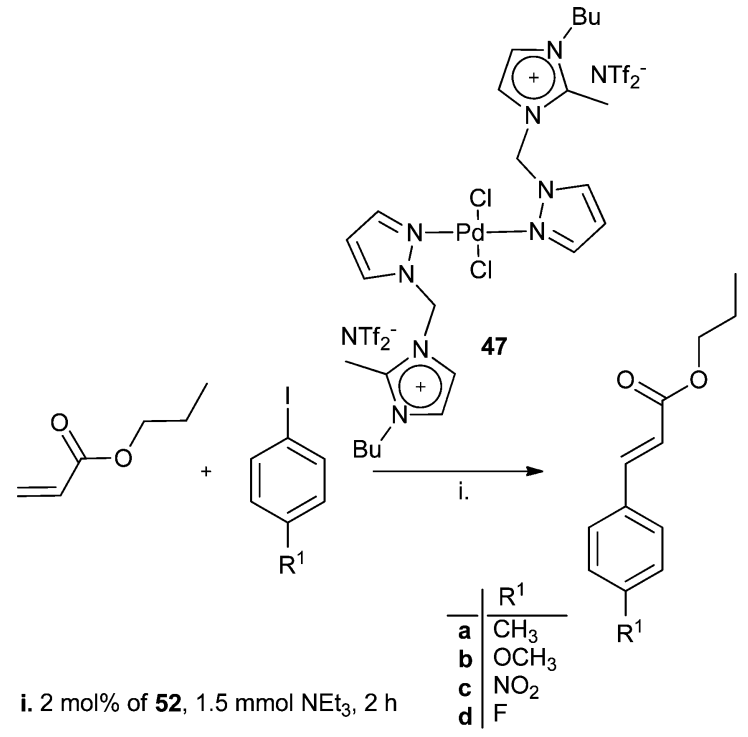

Scheme 24

solution was recovered and reused successfully twelve times without any detectable loss of catalytic activity.

Liu and co-workers ${ }^{94}$ reported the synthesis of the $\mathrm{IL}^{-}$ supported diol, [2,2-bis-(1-(1-methylimidazolium)methylpropane-1,3-diol hexafluorophosphate)] $\mathbf{4 8}$ according with the methodology shown in Scheme 25 and tested its efficiency as a free phosphine ligand for Pd-catalyzed Heck-Mizoroki reaction. The authors found that the best results in the coupling of iodobenzene with ethyl acrylate $(100 \%$ conversion and selectivity $98 \%$ ) occurred when the reaction was performed in the presence of $0.05 \mathrm{~mol} \%$ of $\mathrm{PdCl}_{2}$ and $0.1 \mathrm{~mol} \%$ of 48 , in DMF at $130{ }^{\circ} \mathrm{C}$, using $\mathrm{K}_{2} \mathrm{CO}_{3}$ as a base. The high performance of the system was maintained when other aryl iodides or bromides and acrylates were studied. The authors referred that the catalytical activity $\mathrm{PdCl}_{2}-\mathbf{4 8}$ is maintained even after ten cycles without any precipitation and Pd leaching. However, attempts to use the electro-deficient $p$-chloronitrobenzene were not well succeeded.

Soon afterwards the same group ${ }^{95}$ reported the synthesis of another diol based on imidazole, the 1-(2,3-dihydroxypropyl)-3methylimidazolium hexafluorophosphate (49) (Fig. 9). Under

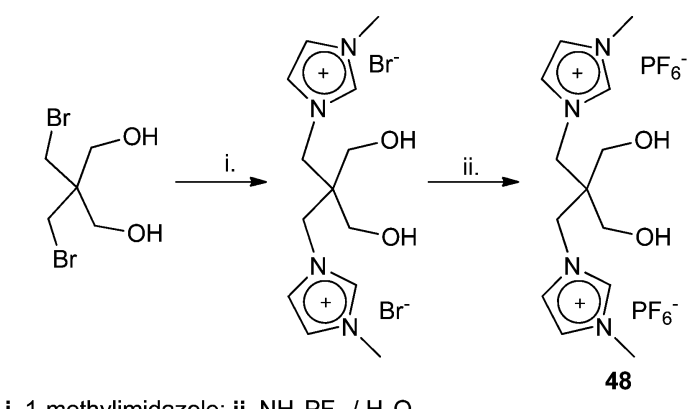

i. 1-methylimidazole; ii. $\mathrm{NH}_{4} \mathrm{PF}_{6} / \mathrm{H}_{2} \mathrm{O}$

Scheme 25 


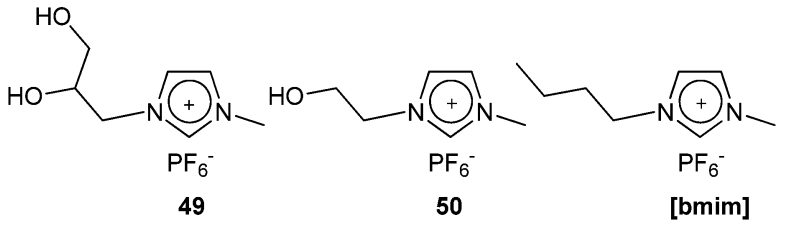

Fig. 9 Structure of imidazole based ILs.

the conditions established in the previous manuscript, this IL is also an efficient and reusable phosphine-free ligand for palladium catalyzed Heck-Mizoroki reactions. The couplings of a variety of aryl iodides/aryl bromides with acrylates generated the corresponding products in good/excellent yields even in aerial atmosphere. In addition, the palladium catalyst mediated by 49 could be easily recovered and reused for ten runs without loss of its activity. The inefficacy of ligands $\mathbf{5 0}$ and $[\mathrm{bmim}]\left[\mathrm{PF}_{6}\right]$ during their recycling uses along with the precipitation of Pd black confirm the importance of the multiple ligations present in ligand 49.

Full results concerning the efficacy of both TSILs were the subject of another publication by this group, in the same period. $^{96}$

Dyson et $a l .{ }^{90}$ reported in 2007 the catalytical activity of $\mathrm{PdCl}_{2}$ in carbon-carbon coupling reactions using a series of nitrile-functionalized imidazolium salts. Considering the Heck-Mizoroki coupling the authors selected the TSIL 1-alkylnitrile-3-methylimidazolium hexafluorophosphate (51) that was obtained in high yield (92\%), from the reaction of 1-methylimidazole with chloropropylnitrile followed by the metathetic exchange of the anion chloride with $\mathrm{HPF}_{6}$ (Fig. 10).

The reactivity of the salt with different counter anions was studied in the presence of $\mathrm{PdCl}_{2}$ affording salts bearing a tetrachloropalladate anion (Fig. 10) or compounds in which the nitrile substituent coordinates to the palladium center.

It was observed that the Heck-Mizoroki reaction between iodobenzene or clorobenzene and ethyl acrylate in the nitrileTSIL 51 in the presence of $\mathrm{PdCl}_{2}$ or of complex 52 using [cholinium][OAc] as base only gave quantitative conversion of iodobenzene into the corresponding cinnamate in the presence of $\mathrm{HCO}_{2} \mathrm{NH}_{4}$. The authors justified this behaviour by the high stabilization of the complexes or due to the rapid inactivation of the system. The reuse of the TSIL system was not very encouraging since it was observed a progressive loss of activity, but the addition of [cholinium][OAc] after the fourth run restored the reactivity of the system.

To overcome the problems arising from the depletion of the base during the recycles, Shreeve and co-workers considered in

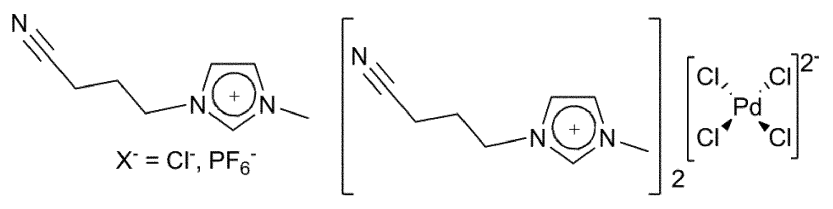
51 52

Fig. 10 TSIL Pd complex $\mathbf{5 2}$ and their TSIL precursor $\mathbf{5 1 .}$

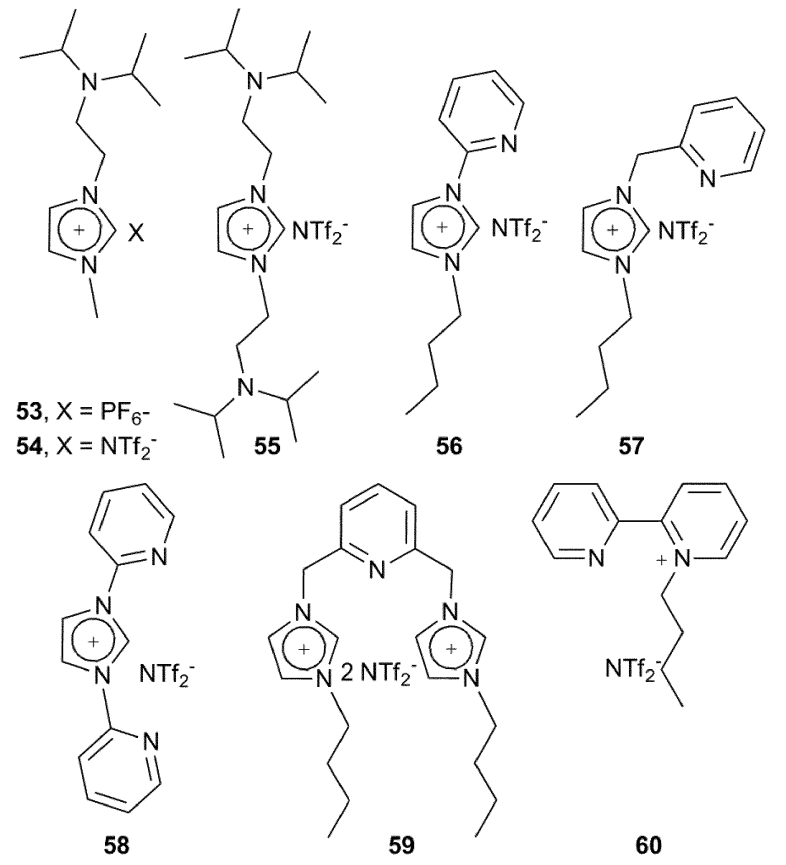

Fig. 11 Structures of basic ILs.

2007, the possibility of using basic ILs as solvent and base in Heck-Mizoroki couplings. ${ }^{97}$ The authors selected a series of basic liquids (Fig. 11) and tested their efficacy in the reaction of iodobenzene with butyl acrylate in the presence of palladium acetate $(1 \mathrm{~mol} \%)$ at $110{ }^{\circ} \mathrm{C}$ (Table 6). The results, obtained showed that the efficiency of the process is superior in the presence of ILs bearing tertiary amines, when compared with the ones bearing pyridines units. It was reported that the catalytic system can be reused at least five times after its recovering by a simple washing with $\mathrm{NaHCO}_{3}$. For bromoarenes $\mathrm{PdCl}_{2}\left(\mathrm{PPh}_{3}\right)_{2}$ exhibits better reactivity in the presence of 54.

Attempts to synthesize carbene-palladium complexes by refluxing eight equivalent of basic IL 53 and $\mathrm{Pd}(\mathrm{OAc})_{2}$ in THF or acetone afforded nanoparticles that show poor efficacy in the coupling of bromobenzene and butyl acrylate. The high temperature is responsible for the agglomeration of nanoparticles affording palladium black. In the presence of $\mathrm{PdCl}_{2}\left(\mathrm{PPh}_{3}\right)_{2}$, the spectroscopic data suggest the possible formation of a carbene/ $\mathrm{Pd} / \mathrm{PPh}_{3}$ complex.

Li et al. ${ }^{98}$ reported the development of TSIL 62 from commercially available reagents (Scheme 26) that showed a high activity and recyclability in palladium-catalyzed HeckMizoroki reactions involving not only iodoarenes and bromoarenes but also chloroarenes. The synthetic approach to the

Table 6 Heck Mizoroki reaction of butyl acrylate with iodobenzene catalyzed by $1 \mathrm{~mol} \%$ of $\mathrm{Pd}(\mathrm{OAc})_{2}$ in the presence of basic ILs

\begin{tabular}{lcccccccc} 
IL & 53 & 54 & 55 & 56 & 57 & 58 & 59 & 60 \\
\hline \% conversion & 100 & 100 & 100 & 0 & 41 & 0 & 5 & 0
\end{tabular}



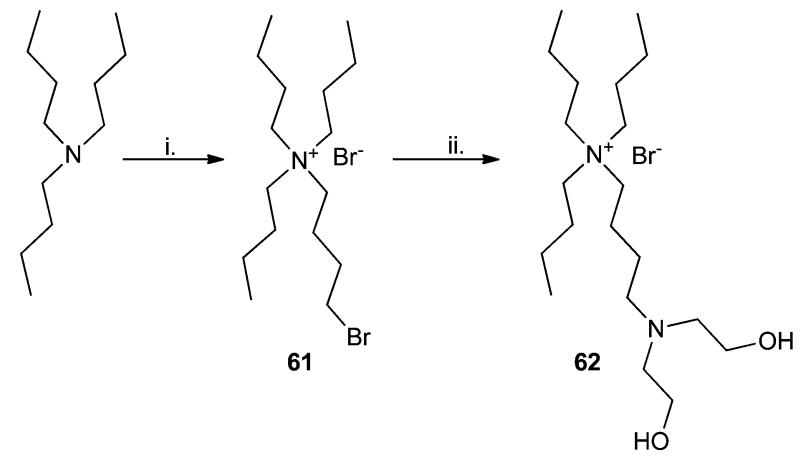

i. 1,4-dibromobutane,ethanol, reflux; ii. diethanolamine, ethanol, $\mathrm{Na}_{2} \mathrm{CO}_{3}$

Scheme 26

4-di(hydroxyethyl)aminobutyltributylammonium bromide $\mathbf{6 2}$ included the reaction of tributylamine with 1,4-dibromobutane that was followed by the reaction with diethanolamine. In both steps the products $\mathbf{6 1}$ and $\mathbf{6 2}$ were obtained in yields higher than $90 \%$.

The activity of the TSIL 62 was examined in the absence of any additive and the authors found that the best palladium sources for the Heck-Mizoroki coupling were $\mathrm{Pd}(\mathrm{OAc})_{2}$ and $\mathrm{PdCl}_{2}$. In this reaction medium, the coupling of bromobenzene and styrene in the presence of those catalysts ( $1 \mathrm{~mol} \%)$ afforded after $6 \mathrm{~h}$ at $100{ }^{\circ} \mathrm{C}$ the trans-stilbene in yields higher than $96 \%$. Good to excellent results (82-99\%) were also reported when the scope of the procedure was examined with a wide range of iodoarenes, bromoarenes, heteroarylbromides and activated chloroarenes like $p$-cyano and $p$-acetylchlorobenzene. A moderate yield of $66 \%$ was reported for the coupling with chlorobenzene. The authors highlighted that palladium can be easily recycled and reused with the same efficiency for six cycles.

The possibility of using triethanolammonium acetate [TEA][HOAc] as a reaction medium, base, precatalyst and mobile support for active Pd species in Heck-Mizoroki reaction was also considered. ${ }^{99}$ The results showed that the coupling of iodobenzene or bromobenzene with different acrylates in the presence of $2 \mathrm{~mol} \% \mathrm{PdCl}_{2}$ at $100{ }^{\circ} \mathrm{C}$ is superior in that IL when compared with the one performed just in triethanolamine, under the same reaction conditions. It was also mentioned that the reaction products can be separated easily by extraction and the IL-palladium catalytic system can be recycled three times. The examination of the mechanism using density functional theory (DFT calculations) suggested that two $\mathrm{Pd}(\mathrm{II})$ complexes involving $\mathrm{Pd}-\mathrm{N}, \mathrm{N}$ and $\mathrm{Pd}-\mathrm{N}, \mathrm{O}$ linkages are formed but only this last can act as a precatalyst, yielding the catalytically active $\operatorname{Pd}(0)$ species.

A different strategy was considered by Vaultier and coworkers that use task specific onium salt as soluble supports for the Heck-Mizoroki substrates, the olefins or the aryl iodides. $^{100}$

The coupling of acryloyl chloride with different $\varpi$-hydroxylated onium salts $\mathbf{6 3}$ afforded the corresponding supported onium salts 64 bearing cations such as trimethylammonium,

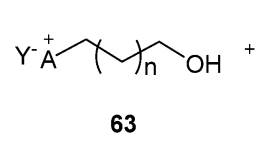<smiles>C=CC(=O)Cl</smiles><smiles>CC(C)C</smiles><smiles>[Y2]CCCOC(=O)C=C</smiles>

i. $\mathrm{CH}_{3} \mathrm{CN}, \mathrm{K}_{2} \mathrm{CO}_{3}, \Delta$ $\mathrm{A}=\left\{\begin{array}{l}\mathrm{N}\left(\mathrm{CH}_{3}\right)_{3} \\ \mathrm{Pyridine} \\ \mathrm{Bu}_{3} \mathrm{P} \\ \mathrm{Methylimidazolium}\end{array}\right.$
$\mathrm{n}=0,1,2,4$
$\mathrm{Y}=\mathrm{NTf}_{2} ; \mathrm{BF}_{4} ; \mathrm{PF}_{6} ; \mathrm{Br}$

Scheme 27

pyridinium, tributylphosphonium or imidazolium (Scheme 27).

Using a similar approach but now recurring to the benzoylation of $N, N$-dimethyl-1-aminobutan-4-ol 65 with 4-iodobenzoyl chloride, followed by quaternization of tertiary amine 66 afforded the supported iodoarenes 67 bearing a counter anion depending on the reagent used for methylation (triflate, iodide, methylsulfate). More diversity was introduced by a simple ion metathesis in water leading to triflimide, hexafluorophosphate and tetrafluoroborate analogs 68 (Scheme 28).

The preliminary Heck-Mizoroki coupling experiments involving the supported olefin $\mathbf{6 4}$ and iodobenzene were conducted in both IL and molecular solvents, in the presence of $1 \%$ of $\left[\mathrm{Pd}(\mathrm{OAc})_{2}\right]$ as catalyst and potassium carbonate as base (Scheme 29). Quantitative conversions were obtained in $[$ tmba $]\left[\mathrm{NTf}_{2}\right]$ and $[$ emim $]\left[\mathrm{NTf}_{2}\right]$ after $2 \mathrm{~h}$ at $110{ }^{\circ} \mathrm{C}$, but only $70 \%$ were observed in acetonitrile. Also, $E / Z$ selectivity was highly superior in ILs as only the $(E)$-isomer is observed where $12 \%$ of the $(Z)$-compound was obtained in $\mathrm{CH}_{3} \mathrm{CN}$. The authors reported also that the supported acrylate is much more reactive than the corresponding methyl ester as a poor conversion of $26 \%$ was obtained when this acrylate was used under the same conditions in acetonitrile.

The authors found that by just heating a mixture of $0.1 \%$ $\left[\mathrm{Pd}(\mathrm{OAc})_{2}\right]$ in $[\mathrm{tmba}]\left[\mathrm{PF}_{6}\right]$ above its melting point (m.p. $=156$ ${ }^{\circ} \mathrm{C}$ ) under inert atmosphere afforded a grey powder composed of palladium nanoparticles $(4 \mathrm{~nm})$ Pd-CAT that can be used

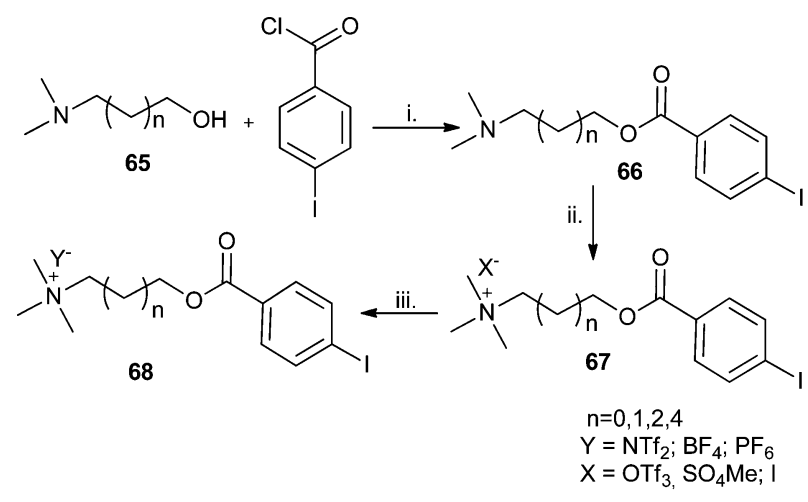

i. $\mathrm{K}_{2} \mathrm{CO}_{3}, \mathrm{CH}_{2} \mathrm{Cl}_{2}$, rt; ii. $\mathrm{CH}_{3} \mathrm{X}, \mathrm{CH}_{3} \mathrm{CN}$, rt; iii. LiY or $\mathrm{HY}, \mathrm{H}_{2} \mathrm{O}$, rt 


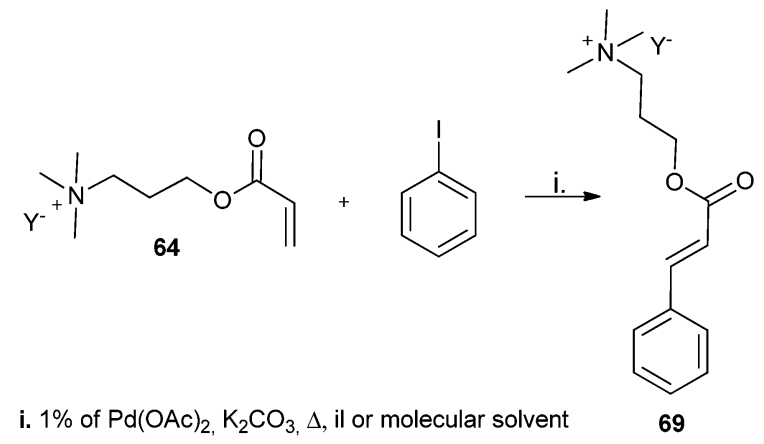

Scheme 29

directly to catalyze Heck-Mizoroki reactions. The best results were obtained when the coupling of the supported substrates was performed in [tmba] $\left[\mathrm{PF}_{6}\right]$ at $110{ }^{\circ} \mathrm{C}$, using only $1 \mathrm{ppm}$ of Pd-CAT (Scheme 30). After transesterification, the Binary Task Specific ILs could be recycled several times without loss of matter beside other than mechanical loss during solid transfer. The methodology was validated by extending the approach to other iodobenzenes.

Efficient results were also achieved by $\mathrm{Lu}$ et al. ${ }^{101}$ which used recyclable TSIL catalytic system based on an imidazolium sulfonated triphenylposphine salt [bmim][tppms] in the presence of $[\mathrm{bmim}][\mathrm{OAc}]$ and $\mathrm{PdCl}_{2}\left(\mathrm{CH}_{3} \mathrm{CN}\right)_{2}$, to catalyze coupling reactions involving a wide range of aryl halides and olefins. Recycling studies showed no loss of catalytical activity
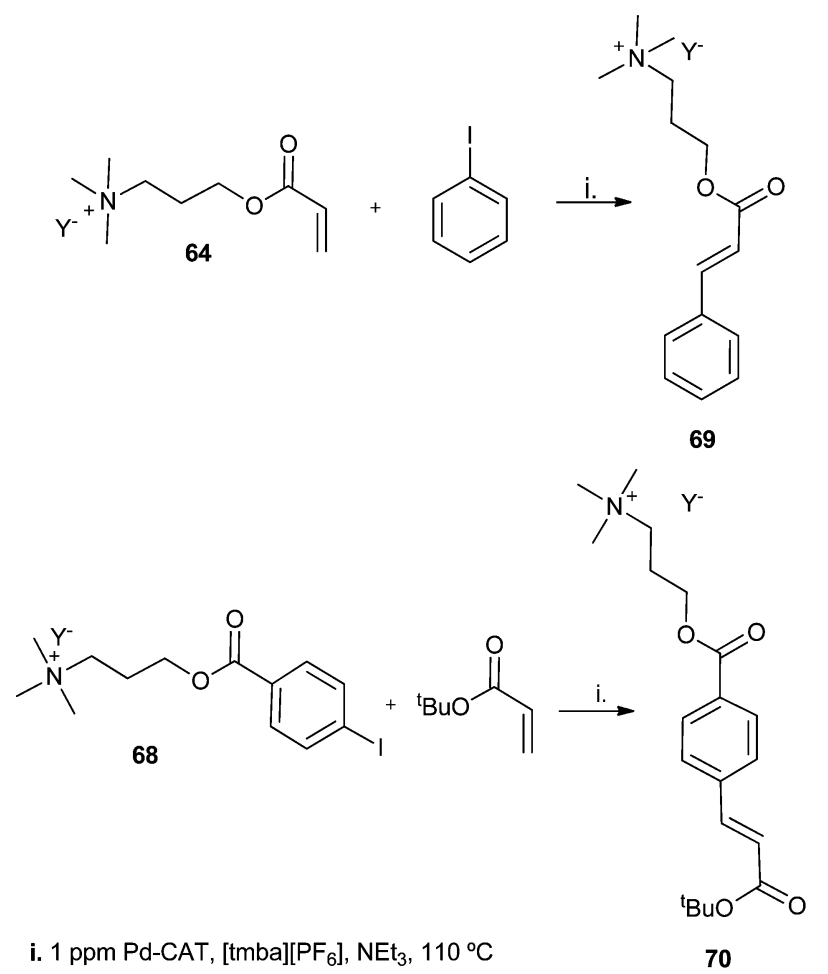

Scheme 30 even after 11 cycles in reactions involving bromobenzene and ethyl acrylate.

\section{Heck-Mizoroki Reaction in ILs mediated by microwave irradiation}

Although some exciting results about Heck-Mizoroki reaction in ILs have been verified, usually, long reaction times are required. In order to solve this limitation, the possibility of using microwave (MW) irradiation associated with ILs was considered by several groups. The dipole characteristics of IL translate into rapid excitation by MWs and consequently faster reactions are usually obtained.

In fact, MW is known to accelerate many organic reactions in polar solvents such as DMF, water, etc. A limited number of MW-assisted Heck-Mizoroki reactions have been reported and in general aryl iodides and active aryl bromide have been tested. ${ }^{92-96}$

In 2002 Larhed and co-workers, ${ }^{102}$ based on their previous studies concerning the use of MW irradiation to accelerate palladium coupling reactions, ${ }^{103}$ assessed the possibility of performing Heck-Mizoroki arylations in IL under that type of irradiation. The authors selected for the studies the IL [bmim $]\left[\mathrm{PF}_{6}\right]$ due to its recognized efficiency for palladium(0)catalyzed coupling reactions, and the initial studies were performed between the deactivated bromoanisole and butyl acrylate. The reactions were carried out in sealed vials, for 45 min, at $180{ }^{\circ} \mathrm{C}$ under $\mathrm{MW}$ irradiation in the presence of different palladium sources and phosphine ligands. The authors found that under the conditions selected, the combination of $\mathrm{PdCl}_{2}$ with $\mathrm{P}(o \text {-tol })_{3}$ led to the best yield of the expected product (99\%). This catalytic system was extended to other aryl and heteroaryl halides and after further time-optimizations, the couplings were efficiently performed within 5-45 min of heating at reaction temperatures of 180$220{ }^{\circ} \mathrm{C}$. The recyclability of the catalytic ionic system was studied with iodobenzene and butyl acrylate in the presence of $\mathrm{PdCl}_{2}$ with no phosphine ligand present; it was found that the ionic catalyst phase was recyclable in five successive $20 \mathrm{~min}$ reactions, at $180{ }^{\circ} \mathrm{C}$ and the product was easily separated by rapid distillation under reduced pressure.

Pan et $a .^{104}$ selected the IL 1-octyl-3-methylimidazolium tetrafluoroborate $[\mathrm{omim}]\left[\mathrm{BF}_{4}\right]$ to conduct Heck-Mizoroki reactions in the absence of phosphine ligands under MW heating. The coupling involving different aryl halides (aryl iodides and aryl bromides) and butyl acrylate were conducted in an open system with 3 or $5 \mathrm{~mol} \%$ of $\mathrm{Pd} / \mathrm{C}$ as catalyst in the presence of tributylamine and under MW irradiation (225 or $375 \mathrm{~W})$ during $1.5 \mathrm{~min}$. The yields of the trans-butyl cinnamates products varied between 33 to $89 \%$. The scope of the catalytic conditions was extended also to the arylation of other olefins (styrene, 2-methylbutyl acrylate and methyl cinnamate) with iodobenzene where it was observed that the steric effects played a role in the coupling; the yield of the product obtained with methyl cinnamate was only $27 \%$, while with the others olefins varied between 70 and $86 \%$. The authors reported that the IL containing the catalyst system can be used five times with a small loss of activity and the products can be extracted by diethyl ether and purified by column chromatography. The authors referred that couplings invol- 


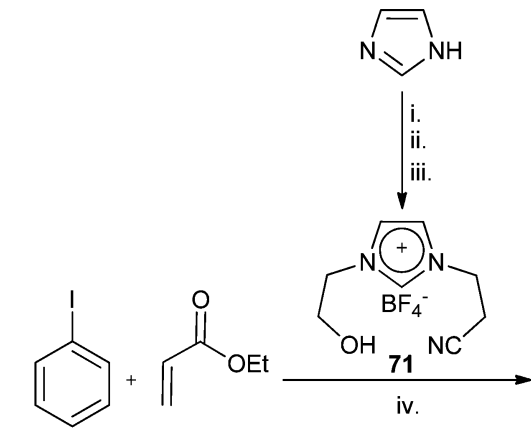

i. acrylonitrile, $\mathrm{CH}_{3} \mathrm{OH}$, reflux, $24 \mathrm{~h}$;

ii. chloromethanol, $\mathrm{CH}_{3} \mathrm{OH}$, reflux $48 \mathrm{~h}$;

iii. $\mathrm{NaBF}_{4} / \mathrm{rt}, 48 \mathrm{~h}$

iv. $\mathrm{PdCl}_{2}, \mathrm{MW}, \Delta$

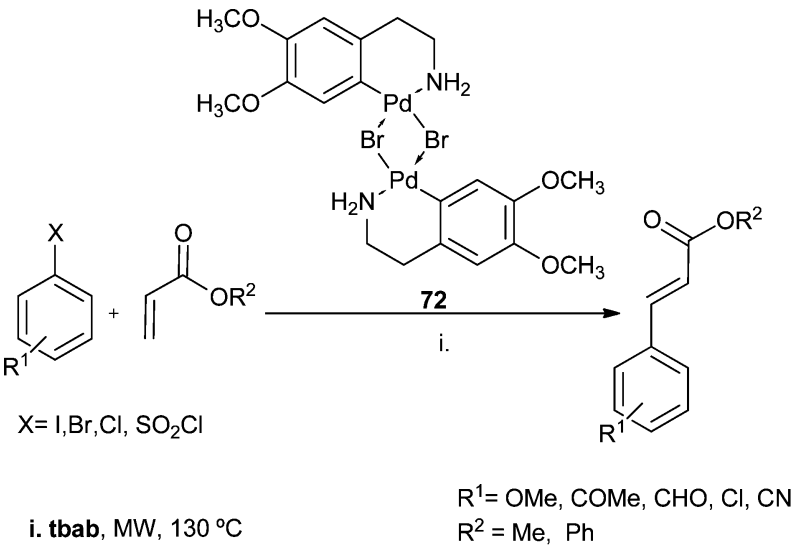

Scheme 32
Scheme 31

ving aryl chlorides and butyl acrylate were only successful when $p$-nitrochlorobenzene was used; in this case the expected cinnamate was obtained in $42 \%$ yield after 2 min of MW irradiation with a power of $375 \mathrm{~W}$.

Degani et al. ${ }^{105}$ reported that the efficiency of HeckMizoroki couplings performed in the TSIL 1-(2-cyanoethyl)-3(2-hydroxyethyl)-1 $H$-imidazol-3-ium tetrafluoroborate (71) (Scheme 31) in the presence of $\mathrm{PdCl}_{2}$ can be highly improved under MW irradiation. For instance, under conventional heating $\left(100{ }^{\circ} \mathrm{C}\right)$ the coupling of iodobenzene with ethyl acrylate using that catalyst system (71) afforded, after $24 \mathrm{~h}$, the expected $(E)$-ethyl cinnamate in a modest yield of $25 \%$. A different situation occurred, after $5 \mathrm{~min}$ of MW irradiation $(200 \mathrm{~W})$ at $120{ }^{\circ} \mathrm{C}$, where a significant increase to $84 \%$ was obtained for the expected cinnamate.

The versatility of the optimized catalytic system for HeckMizoroki reaction was extended to other activated and deactivated iodoarenes and bromoarenes including sterically ones, and also to other acrylates and styrene. The expected products were obtained after 5 to $10 \mathrm{~min}$ of reaction in yields ranging from 53 to $88 \%$. The system showed good stability and maintained the efficiency after six consecutive runs without significant loss of activity (Table 7 ).

The combination of the dimeric orthopalladate complex $\mathbf{7 2}$ with the molten salt tbab showed to be an efficient catalyst system for Heck-Mizoroki reaction of aryl bromides, aryl iodides, aryl chlorides and arenesulfonyl chlorides under

Table 7 Isolated Yield (\%) of (E) ethyl cinnamate from Pd(II) catalyzed Heck Mizoroki reaction $^{a}$

\begin{tabular}{lllllll}
\hline & \multicolumn{7}{l}{ Run } \\
\cline { 2 - 7 } Entry & 1 & 2 & 3 & 4 & 5 & 6 \\
\hline $\mathbf{1}$ & 84 & 84 & 83 & 83 & 82 & 80 \\
2 & 83 & 82 & 82 & 82 & 80 & 80
\end{tabular}

${ }^{a} 0.01 \mathrm{mmol} \mathrm{PdCl}_{2}, 2.0 \mathrm{~mL}$ of $711.0 \mathrm{mmol} \mathrm{Ph} \mathrm{I,} 2.0 \mathrm{mmol}$ ethyl acrylate, $200 \mathrm{~W}$ of $\mathrm{MW}$ power, $120^{\circ} \mathrm{C}, 5 \mathrm{~min}$ of reaction. conventional heating and microwave irradiation (Scheme 32). ${ }^{106}$ The authors reported a significant improvement in the reaction times under MW (from hours in conventional heating to minutes under MW) that was justified by the dipole characteristics of tbab that is able to translate into rapid excitation by MWs and consequently to allow faster reactions to occur.

MW irradiation was found crucial to develop ${ }^{107}$ a waste-free strategy for Tandem synthesis of stilbenoids (73) involving a dehydrative Heck-Mizoroki sequence from secondary aryl alcohols assisted by the IL 1-hexyl-3-methylimidazolium bromide [hmim] $[\mathrm{Br}]$. After a detailed optimization of the experimental conditions the authors found that the presence of a IL is fundamental for an efficient dehydration of the alcohols and [hmim] $[\mathrm{Br}]$ is the most efficient one (Scheme 33). The best yield was obtained in the presence of $\left[\mathrm{PdCl}_{2}\left(\mathrm{PPh}_{3}\right)_{2}\right]$ along with $\mathrm{LiCl}$ and the combination of the two bases $\mathrm{HCO}_{2} \mathrm{Na}$ and piperidine allowed to reduce reaction times from $40 \mathrm{~min}$ to $15 \mathrm{~min}$ (Scheme 33).

The results suggest that mechanistically the in situ formation of the incipient styrene is assisted by IL/MW that simultaneously undergoes palladium-catalyzed cross-coupling with the aryl halide affording stilbenes in one pot (Fig. 12). The creation of microscopic hot spots (having temperature well above $150{ }^{\circ} \mathrm{C}$ ) can justify the higher efficiency of MW irradiation when compared with conventional heating $(69 \%$ versus $20 \%$ ).<smiles>COc1ccc(/C=C/c2ccc3ccccc3c2)cc1</smiles>

73 


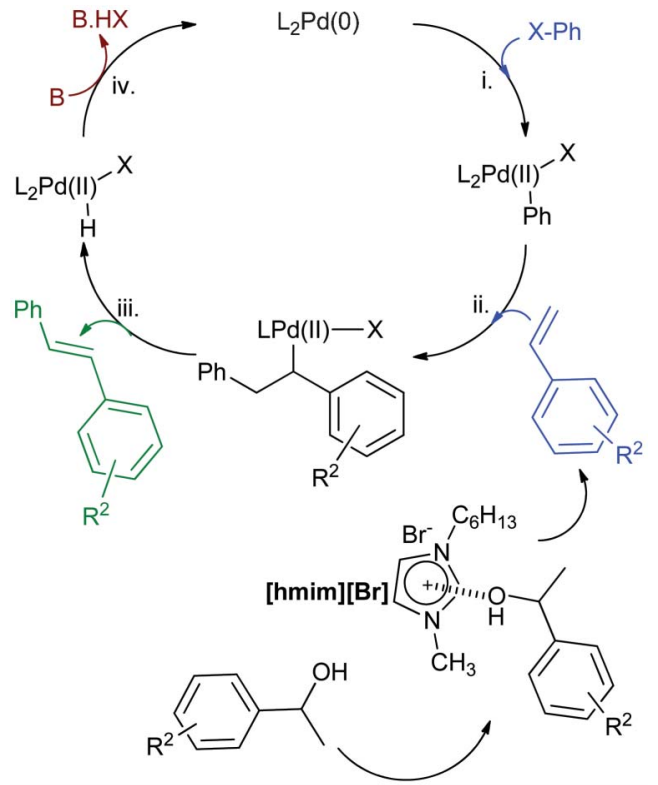

Fig. 12 Proposed mechanism for Tandem dehydrative Heck Mizoroki reaction in an IL under MW irradiation.

A catalytical system based on $\operatorname{Pd}_{2}(\mathrm{dba})_{3}(\mathrm{dba}=$ dibenzylideneacetone) and on the phosphine ligand (74) showed to be effective in Heck-Mizoroki cross-coupling involving aryl iodides, bromides and chlorides with different olefins when the reaction was performed in $\mathrm{DMSO} /[\mathrm{bmim}]\left[\mathrm{BF}_{4}\right]$ and under MW irradiation (Scheme 34). When compared to the conventional heating, it was observed a reduction on reaction times from hours to minutes and the desired products were obtained in near quantitative yields in the presence of lower catalyst loading. ${ }^{108}$

\section{Conclusions}

The search of more sustainable procedures prompted organic chemists to look for more eco-compatible and more econom-

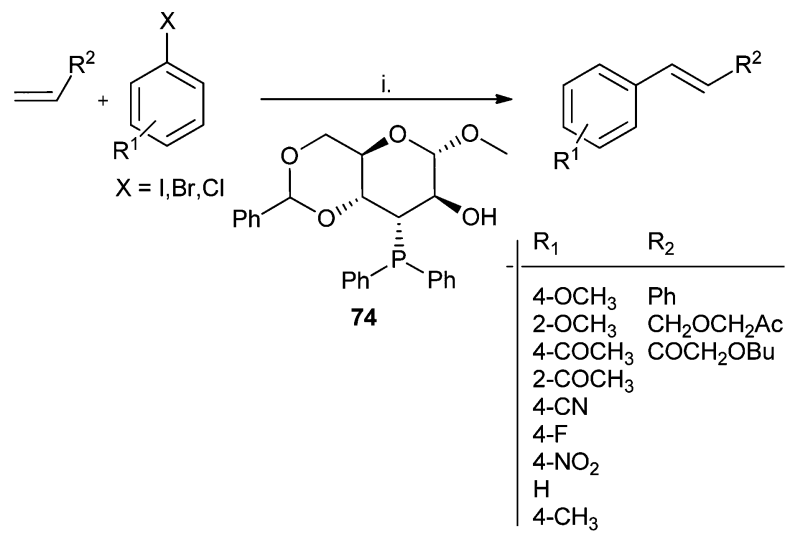

i. $5.0 \mathrm{~mol} \%$ [bmim] $\left[\mathrm{BF}_{4}\right], \mathrm{DMSO}, \mathrm{K}_{2} \mathrm{CO}_{3}, 0.01 \mathrm{~mol} \%$ of $\left[\mathrm{Pd}_{2}(\mathrm{dba})_{3}: \mathbf{7 4 = 1 : 2}\right.$, MW, $350 \mathrm{~W}$ ical transition metal-catalyzed reactions. In the last ten years a high number of palladium catalyzed Heck-Mizoroki studies in ILs were reported as a possible green alternative to the classical cross-coupling procedure.

Homogeneous and heterogeneous conditions under conventional or MW heating have been considered and the results show that ILs are able to modify the reaction course and to activate and stabilize intermediates or transitions states.

Although there are high numbers of studies considering Heck-Mizoroki reaction in ILs, most of the works involve the coupling of simple aryl halides and olefins. Thus, in the future, it is expected that the use of ILs in Heck-Mizoroki reactions can involve more complicated substrates affording environmentally benign chemical processes.

\section{Acknowledgements}

Authors are grateful to Fundação para a Ciência e a Tecnologia (FCT, Portugal), European Union, QREN, FEDER and COMPETE for funding the QOPNA research unit (project PEst-C/QUI/UI0062/2011) and Scientific Association Proteomass (Portugal). C.S. and J.B. thank also to FCTMCTES (Portugal) by their Doctoral and Post-Doctoral grants, SFRH/BD/64155/2009 and SFRH/BPD/63237/2009.

\section{References}

1 T. Welton, Chem. Rev., 1999, 99, 2071-2083.

2 J. P. Hallett and T. Welton, Chem. Rev., 2011, 111, 3508-3576.

3 N. V. Plechkova and K. R. Seddon, Chem. Soc. Rev., 2008, 37, 123-150.

$4 \mathrm{H}$. Olivier-Bourbigou and L. Magna, J. Mol. Catal. A: Chem., 2002, 182(183), 419-437.

5 J. Dupont, F. Souza and Z. Suarez, Chem. Rev., 2002, 102, 3667-3692.

6 R. Sebesta, I. Kmentova and S. Toma, Green Chem., 2008, 10, 484-496.

7 P. Wasserscheid and W. Keim, Angew. Chem., Int. Ed., 2000, 39, 3772-3789.

8 H. Olivier-Bourbigou and L. Magna, Appl. Catal., A, 2010, 373, 1-56.

9 C. Gordon, Appl. Catal., A, 2001, 222, 101-117.

10 P. Walden, Bull. Acad. Imp. Sci. St Petersbourg, 1914, 405-422.

11 J. S. Wilkes, J. A. Levisky, R. A. Wilson and C. L. Hussey, Inorg. Chem., 1982, 21, 1263-1265.

12 A. E. Visser, R. P. Swatloski, W. M. Reichert, R. Mayton, S. Sheff, A. Wierzbicki, J. H. Davis Jr. and R. D. Rogers, Chem. Commun., 2001, 135-136.

13 K. Fukumoto, M. Yoshizawa and H. Ohno, J. Am. Chem. Soc., 2005, 127, 2398-2399.

14 D. Zhao, Z. Fei, T. J. Geldbach, R. Scopelliti and P. J. Dyson, J. Am. Chem. Soc., 2004, 126, 15876-15882.

15 A. C. Cole, J. L. Jensen, I. Ntai, K. L. T. Tran, K. J. Weaver, D. C. Forbes and J. H. Davis Jr., J. Am. Chem. Soc., 2002, 124, 5962-5963. 
16 S. G. Lee, Chem. Commun., 2006, 1049-1063.

17 P. Wasserscheid, B. Driessen-Hölscher, R. van Hal, H. C. Steffers and J. Zimmerman, Chem. Commun., 2003, 2038-2039.

18 W. Bao, Z. Wang and Y. Li, J. Org. Chem., 2003, 68, 591-593.

19 J. Holbrey, M. B. Turner, W. M. Reichert and R. Rogers, Green Chem., 2003, 5, 731-736.

20 S. Himmler, A. König and P. Wasserscheid, Green Chem., 2007, 9, 935-939.

21 V. Polshettiwar and R. S. Varma, Acc. Chem. Res., 2008, 41, 629-639.

22 S. Keskin, D. Kayrak-Tallay, U. Akman and Ö. Hortaçsu, J. Supercrit. Fluids, 2007, 43, 150-180.

23 R. Singh, M. Sharma, R. Mamgain and D. S. Rawat, J. Braz. Chem. Soc., 2008, 19, 357-379.

24 N. Jain, A. Kumar, S. Chauhan and S. M. S. Chauhan, Tetrahedron, 2005, 61, 1015-1060.

25 J.-C. Hsu, Y.-H. Yen and Y.-H. Chu, Tetrahedron Lett., 2004, 45, 4673-4676.

26 V. I. Parvulescu and C. Hardacre, Chem. Rev., 2007, 107, 2615-2665.

27 S. Liu and J. Xiao, J. Mol. Catal. A: Chem., 2007, 270, 1-43.

28 J. P. Hallett and T. Welton, Chem. Rev., 2011, 111, 3508-3576.

29 H. Li, P. S. Bhadury, B. Song and S. Yang, RSC Adv., 2012, 2, 12525-12551.

30 Q. Zhang, S. Zhang and Y. Deng, Green Chem., 2011, 13, 2619-2637.

31 F. Alonso, I. P. Beletskaya and M. Yus, Tetrahedron, 2005, 61, 11771-11835.

$32 \mathrm{~J}$. Tsuji in Palladium Reagents and catalysts, Innovations in organic synthesis, Wiley-VCH, New York, 1995.

33 J. Mo, S. Liu and J. Xiao, Tetrahedron, 2005, 61, 9902-9907.

34 H. Vallette, S. Pican, C. Boudou, J. Levillain, J.C. Plaquevent and A.-C. Gaumont, Tetrahedron Lett., 2006, 47, 5191-5193.

35 S. Bouquillon, B. Ganchegui, B. Estrine, F. Henin and J. Muzart, J. Organomet. Chem., 2001, 634, 153-156.

36 L. Xu, W. Chen, J. Ross and J. Xiao, Org. Lett., 2001, 3, 295-297.

37 T. Mizoroki, K. Mori and A. Ozaki, Bull. Chem. Soc. Jpn., 1971, 44, 581-581.

38 R. Heck and J. Nolley, J. Org. Chem., 1972, 37, 2320-2322.

39 http://www.nobelprize.org/nobel prizes/chemistry/laureates $/ 2010 /$

40 X.-F. Wu, P. Anbarasan, H. Neumann and M. Beller, Angew. Chem., Int. Ed., 2010, 49, 9047-9050.

41 I. Beletskaya and A. Cheprakov, Chem. Rev., 2000, 100, 3009-3066.

42 M. G. P. M. S. Neves, M. M. Q. Simões and J. A. S. Cavaleiro in Catalysis from Theory to Application, J. Figueiredo, M. Pereira and J. Faria, Universidade de Coimbra, 2008, pp. 355-377.

43 J. Clayden, N. Greeves and S. Warren, Organic Chemistry, 2nd, Oxford University Press,, Oxford, 2001.

44 V. Calò, A. Nacci and A. Monopoli, Eur. J. Org. Chem., 2006, 3791-3802.

45 A. H. M. de Vries, F. J. Parlevliet, L. Schmieder-van de Vondervoort, J. H. M. Mommers, H. J. W. Henderickx, M.
A. M. Walet and J. G. de Vries, Adv. Synth. Catal., 2002, 344, 996-1002.

46 M. T. Reetz and E. Westermann, Angew. Chem., Int. Ed., 2000, 39, 165-168.

47 N. V. Plechkova and K. R. Seddon, Chem. Soc. Rev., 2008, 37, 123-150.

48 D. Kaufmann, M. Nouroozian and H. Henze, Synlett, 1996, 1091-1092.

49 A. Carmichael, M. Earle, J. Holbrey and K. Seddon, Org. Lett., 1999, 1, 997-1000.

50 V. P. W. Böhm and W. A. Herrmann, Chem.-Eur. J., 2000, 6, 1017-1025.

51 L. Xu, W. Chen and J. Xiao, Organometallics, 2000, 19, 1123-1127.

52 J. Mo, L. Xu and J. Xiao, J. Am. Chem. Soc., 2005, 127, 751-760.

53 W. Pei, J. Mo and J. Xiao, J. Organomet. Chem., 2005, 690, 3546-3551.

54 J. Mo, L. Xu, J. Ruan, S. Liu and J. Xiao, Chem. Commun., 2006, 3591-3593.

55 Z. Hyder, J. Mo and J. Xiao, Adv. Synth. Catal., 2006, 348, 1699-1704.

56 J. Ruan and J. Xiao, Acc. Chem. Res., 2011, 44, 614-626.

57 F. Gayet, J.-D. Marty and N. L. D. Viguerie, ARKIVOC, 2008, xvii, 61-76.

58 J. C. Pastre, Y. Génisson, N. Saffon, J. Dandurand and C. R. D. Correia, J. Braz. Chem. Soc., 2010, 21, 821-836.

59 L. Kiss, T. Kurtan, S. Antus and H. Brunner, ARKIVOC, 2003, v, 69-76.

60 R. Roszak, A. M. Trzeciak, J. Pernak and N. Borucka, Appl. Catal., A, 2011, 409(410), 148-155.

61 D. A. Gerritsma, A. Robertson, J. McNulty and A. Capretta, Tetrahedron Lett., 2004, 45, 7629-7631.

62 M. H. G. Prechtl, J. D. Scholten and J. Dupont in Ionic liquids: applications and perspectives, Prof. Alexander Kokorin, (ed.), Intech, Rijeka, 2011.

63 V. Calò, A. Nacci, A. Monopoli and P. Cotugno, Angew. Chem., Int. Ed., 2009, 48, 6101-6103.

64 V. Calò, A. Nacci, A. Monopoli, A. Detomaso and P. Iliade, Organometallics, 2003, 22, 4193-4197.

65 V. Calò, A. Nacci, A. Monopoli, A. Fornaro, L. Sabbatini, N. Cioffi and N. Ditaranto, Organometallics, 2004, 23, 5154-5158.

66 V. Calò, A. Nacci and A. Monopoli, J. Mol. Catal. A: Chem., 2004, 214, 45-56.

67 C. C. Cassol, A. P. Umpierre, G. Machado, S. I. Wolke and J. Dupont, J. Am. Chem. Soc., 2005, 127, 3298-3299.

68 A. Monopoli, V. Calò, F. Ciminale, P. Cotugno, C. Angelici, N. Cioffi and A. Nacci, J. Org. Chem., 2010, 75, 3908-3911.

69 V. Calò, A. Nacci, A. Monopoli and P. Cotugno, Chem.-Eur. J., 2009, 15, 1272-1279.

70 V. Calò, A. Nacci, A. Monopoli and F. Montingelli, J. Org. Chem., 2005, 70, 6040-6044.

71 P. Cotugno, A. Monopoli, F. Ciminale, N. Cioffi and A. Nacci, Org. Biomol. Chem., 2012, 10, 808-813.

72 X. Shi, X. Han, W. Ma, J. Fan and J. Wei, Appl. Organomet. Chem., 2012, 26, 16-20.

73 V. Singh, R. Ratti and S. Kaur, J. Mol. Catal. A: Chem., 2011, 334, 13-19.

74 W. A. Herrmann, Angew. Chem., Int. Ed., 2002, 41, 1290-1309. 
75 T. Weskamp, V. P. W. Bohm and W. A. Herrmann, J. Organomet. Chem., 2000, 600, 12-22.

76 W. A. Herrmann, M. Elison, J. Fischer, C. Koher and G. R. J. Artus, Angew. Chem., Int. Ed. Engl., 1995, 34, 2371-2374.

77 C. J. Mathews, P. J. Smith, T. Welton, A. J. P. White and D. J. Williams, Organometallics, 2001, 20, 3848-3850.

78 K. Selvakumar, A. Zapf and M. Beller, Org. Lett., 2002, 4, 3031-3033.

79 T.-T. Gao, A-P. Jin and L.-X. Shao, Beilstein J. Org. Chem., 2012, 8, 1916-1919.

80 J.-Y. Lee, P.-Y. Cheng, Y.-H. Tsai, G.-R. Lin, S.-P. Liu, M.H. Sie and H. M. Lee, Organometallics, 2010, 29, 3901-3911.

81 M.-H. Sie, Y.-H. Hsieh, Y.-H. Tsai, J.-R. Wu, S.-J. Chen, P. V. Kumar, J.-H. Lii and H. M. Lee, Organometallics, 2010, 29, 6473-6481.

82 S. Tandukar and A. Sen, J. Mol. Catal. A: Chem., 2007, 268, 112-119.

83 V. Sans, F. Gelat, M. I. Burguete, E. Garcia-Verdugo and S. V. Luis, Catal. Today, 2012, 196, 137-147.

84 R. Kore, M. Tumma and R. Srivastava, Catal. Today, 2012, 198, 189-196.

85 S. Anjaiah, S. Chandrasekhar and R. Grée, Tetrahedron Lett., 2004, 45, 569-571.

86 M. Shibasaki and M. Kanai, Chem. Rev., 2008, 108, 2853-2858.

87 S. Lee, Chem. Commun., 2006, 1049-1063.

88 Z. Fei, T. J. Geldbach, D. Zhao and P. J. Dyson, Chem. Eur. J., 2006, 12, 2123-2129.

89 S. Tang, G. A. Baker and H. Zhao, Chem. Soc. Rev., 2012, 41, 4030-4066.

90 Z. Fei, D. Zhao, D. Pieraccini, W. H. Ang, T. J. Geldbach, R. Scopelliti, C. Chiappe and P. J. Dyson, Organometallics, 2007, 26, 1588-1598.
91 H. Ohno, Bull. Chem. Soc. Jpn., 2006, 76, 1665-1680.

92 A. D. Sawant, D. G. Raut, N. B. Darvatkar and M. M. Salunkhe, Green Chem. Lett. Rev., 2011, 4, 41-54.

93 R. Wang, M. Piekarski and J. Shreeve, Org. Biomol. Chem., 2006, 4, 1878-1886.

94 Y. Q. Cai, Y. Lu, Y. Liu and G. H. Gao, Catal. Lett., 2007, 119, 154-158.

95 Y. Cai, Y. Lu, Y. Liu, M. He and Q. Wan, Catal. Commun., 2008, 9, 1209-1213.

96 Y. Cai and Y. Liu, Catal. Commun., 2009, 10, 1390-1393.

97 C. Ye, J. Xiao, B. Twamley, A. D. LaLonde, M. G. Norton and J. M. Shreeve, Eur. J. Org. Chem., 2007, 5095-5100.

98 L. Wang, H. Li and P. Li, Tetrahedron, 2009, 65, 364-368.

99 Z. D. Petroviæ, S. Markoviæ, V. P. Petroviæ and D. Simijonoviæ, J. Mol. Model., 2012, 18, 433-440.

100 F. Hassine, M. Pucheault and M. Vaultier, C. R. Chim., 2011, 14, 671-679.

101 Y. Liu, M. Li, Y. Lu, G.-H. Gao, Q. Yang and M.-Y. He, Catal. Commun., 2006, 7, 985-989.

102 K. Vallin, P. Emilsson, M. Larhed and A. Hallberg, J. Org. Chem., 2002, 67, 6243-6247.

103 K. Olofsson, M. Larhed and A. Hallberg, J. Org. Chem., 1998, 63, 5076-5079.

104 X. Xie, J. Lu, B. Chen, J. Han, X. She and X. Pan, Tetrahedron Lett., 2004, 45, 809-811.

105 M. G. Dighe and M. S. Degani, ARKIVOC, 2011, xi, 189-197.

106 A. R. Hajipoura and F. Rafieea, Appl. Organomet. Chem., 2011, 25, 542-551.

107 R. Kumar, A. Shard, R. Bharti, Y. Thopate and A. K. Sinha, Angew. Chem., Int. Ed., 2012, 51, 2636-2639.

108 Z. Zhou, Y. Xie, Z. Du, Q. Hu, J. Xue and J. Shib, ARKIVOC, 2012, vi, 164-172. 